\title{
DESIGN, SYNTHESIS, AND ACTIVITY OF 2-IMIDAZOL-1-YLPYRIMIDINE DERIVED INDUCIBLE NITRIC OXIDE SYNTHASE DIMERIZATION INHIBITORS
}

David D. Davey, ${ }^{\dagger}$ Marc Adler, ${ }^{\dagger}$ Damian Arnaiz, ${ }^{\dagger}$ Keith Eagen, ${ }^{\dagger}$ Shawn Erickson, ${ }^{\dagger}$ William Guilford, ${ }^{\dagger}$ Margaret Kenrick, ${ }^{\dagger}$ Michael M. Morrissey, ${ }^{\dagger}$ Mike OhImeyer, ${ }^{\ddagger}$ Gonghua Pan, ${ }^{\ddagger}$ Vidyadhar M. Paradkar, ${ }^{\ddagger}$ John Parkinson, ${ }^{\dagger}$ Mark Polokoff, ${ }^{\dagger}$ Kurt Saionz, ${ }^{\ddagger}$ Cecile Santos, ${ }^{\dagger}$ Babu Subramanyam, ${ }^{\dagger}$ Ron Vergona, ${ }^{\dagger}$ Robert G. Wei, ${ }^{\dagger}$ Marc Whitlow, ${ }^{\dagger}$ Bin Ye, ${ }^{\dagger}$ Zuchun (Spring) Zhao, ${ }^{\dagger}$ James J. Devlin, ${ }^{\dagger}$ Gary Phillips ${ }^{\star}$

\author{
Berlex Biosciences \\ 2600 Hilltop Drive, P.O. Box 4099, Richmond, CA, 94804-0099 \\ Pharmacopeia Drug Discovery, Inc. \\ P.O. Box 5350, Princeton, N.J. 08543-5350
}

*Corresponding author: Tel: (510) 669-4146 Fax: (510) 262-7844 E-mail:

gary phillips@berlex.com

${ }^{\dagger}$ Berlex Biosciences

${ }^{\ddagger}$ Pharmacopeia Drug Discovery 
Abstract: By screening a combinatorial library for inhibitors of nitric oxide (NO) formation by the inducible isoform of nitric oxide synthase (iNOS) using a whole cell assay, a series of 2-(imidazol-1-yl)pyrimidines was identified. Compounds were found to inhibit the dimerization of iNOS monomers, thus preventing the formation of the dimeric, active form of the enzyme. Optimization led to the selection of the potent, selective, and orally available iNOS dimerization inhibitor, $\mathbf{2 1 b}$, which significantly ameliorated adjuvant induced arthritis in a rat model. Analysis of the crystal structure of the $\mathbf{2 1 b}$-iNOS monomer complex provided a rationalization for both the SAR and the mechanism by which $\mathbf{2 1 b}$ blocks the formation of the protein-protein interaction present in the dimeric form of iNOS. 
Nitric Oxide Synthase ${ }^{a}$ (NOS) is a dimeric enzyme that catalyzes the production of NO from arginine using heme, biopterin, and NADPH as cofactors. The three isoforms of NOS, iNOS, endothelial (ecNOS), and neuronal (bcNOS) differ in their tissue distribution and biological role, but are similar in that they are only active in the dimeric form. iNOS is up regulated during an immune response and has been implicated in the pathogenesis of numerous inflammatory diseases, including multiple sclerosis and rheumatoid arthritis. In contrast, bcNOS and ecNOS are constitutively expressed in mammals and are required for normal function. Therefore, a potent inhibitor of iNOS could ameliorate disease, however, high selectivity would be needed to avoid inhibiting the essential functions of the bcNOS and ecNOS isoforms. The potential therapeutic benefit of an iNOS inhibitor has prompted a major effort in the pharmaceutical industry to discover a potent, selective iNOS inhibitor. ${ }^{1,2,3}$

Our initial search for iNOS inhibitors focused on direct enzyme inhibition, specifically compounds that could mimic the substrate, arginine, or those that could directly interact with the heme. The heme binding approach led to the finding that 1 phenylimidazoles were selective, but only moderately potent inhibitors of iNOS,..,5,6 To further explore the phenylimidazole template, a library was prepared using ECLIPS ${ }^{7}$ technology (Figure 1), and screened for direct enzyme inhibitors, but no compounds were identified. The library was screened a second time using a whole-cell assay with NO production as the readout and several library compounds, exemplified by $\mathbf{1}$,

\footnotetext{
a Abbreviations: NOS, nitric oxide synthase; NO, nitric oxide; iNOS, inducible NOS; ecNOS, endothelial constitutive NOS; bcNOS, brain constitutive NOS.
} 
significantly decreased levels of NO production. ${ }^{8}$ On further evaluation, these compounds were found to permeate the cell and inhibit formation of the enzymatically active dimer. Other groups have identified imidazole-containing compounds, that also block NO formation by this mechanism. ${ }^{9,10,11}$ In this paper, we will describe the optimization of the initial hits, identified by screening the library, into orally available, potent, selective iNOS dimerization inhibitors. ${ }^{7,12}$

\section{Chemistry}

Compounds were originally prepared by an efficient method, which required a difficult separation of regioisomeric pyrimidines (Scheme 1). Reaction of 2,4dichloropyrimidine with imidazole gave a mixture of chloro(imidazol-1-yl)pyrimidines, 2 and $\mathbf{3}$, which were separated. The monochloropyrimidines were subsequently reacted with secondary amines to obtain the desired analogs. Due to problems in obtaining sufficient quantities of the desired regioisomers, an alternate synthetic strategy using 2sulfonopyrimidines as an intermediate was developed.

The 2-sulfonopyrimidines were prepared under standard conditions (Scheme 2). Alkylation of the pyrimidinethione, $\mathbf{4}$, with methyl iodide in the presence of base gave methylmercaptan, 5. Reaction of the resulting hydroxypyrimidine with $\mathrm{POCl}_{3}$ resulted in the formation of the corresponding chloropyrimidine, $\mathbf{6}$, which was oxidized with mCPBA to give the sulfone, 7 . The sulfones are not stable and were best used soon after preparation or stored under anhydrous conditions. 
The pyrimidinesulfone was reacted with the protected amines, and the intermediate sulfone, whose isolation is unnecessary but possible, was subsequently reacted with imidazole (Scheme 3). In general, by adding the secondary amine to the chloropyrimidinesulfone and subsequently reacting the intermediate with imidazole, the desired regioisomer was obtained with $>98 \%$ regioselectivity. Under identical conditions, reaction of primary amines with the chloropyrimidinesulfone gave regioisomeric mixtures with addition of the amine at the 4 position predominating (>6:1). Derivatization of the ester or piperazine nitrogen were performed sequentially under standard conditions, by initial deprotection of the ester or amine, depending on the group looking to be modified, to give the desired compounds. The regioisomeric piperazines, 19 , were prepared in a similar manner by starting with the alternatively protected starting piperazine.

The regioselective piperazine synthesis has been described. ${ }^{13}$ Reaction of the ethyl ester of piperazine-2-acetic acid with BOCON places a BOC group on the less hindered piperazine nitrogen. A synthesis of the benzyl protected piperazine has also been described. ${ }^{14} \mathrm{BOC}$ protection of the benzyl protected piperazine gives the diprotected compound. Selective removal of either protecting group gives the selected regioisomer that can be used in the synthesis of any of the piperazine substituted pyrimidines.

The synthesis of optically active $11 \mathbf{d}$ and $19 \mathrm{f}$ was accomplished by separating a precursor on a chiral column. The syntheses were completed by standard methods. 
Absolute stereochemistry was determined by an X-ray crystal structure of $\mathbf{1 1 d}$ and an analogue of $19 f$ bound to the enzyme and all other stereochemistry is inferred. The absolute stereochemistry of $\mathbf{1 1 d}$ corresponds to that of the D-amino acid used as starting material in the syntheses of the more active compounds shown in the pyrrolidine series illustrated in Table 7.

\section{Results and Discussion}

Compounds were initially tested for inhibition of active iNOS formation in a whole cell assay using human A172 cells induced with cytokines. NO formation was monitored spectrophotometrically with the Griess reagent. ${ }^{15}$ All selected compounds were inactive in a standard non-cellular iNOS enzyme assay up to $1 \mu \mathrm{M}$ in which the enzyme had been isolated. ${ }^{16}$ Selectivity between the NOS isoforms was determined using BSC-1 cells transfected with a vaccinia virus system, or SF9 cells transfected with a tetracycline-induced system that expressed one of the three NOS isoforms. In these assays, NOS activity was monitored by measuring the production of radiolabelled citrulline from radiolabelled arginine. The two selectivity assays (vaccinia virus and tetracycline) gave similar results for iNOS potency but different results for ecNOS and bcNOS potency. The relevance of these differences is unknown. ecNOS was found to be more potent in the tetracycline induced system, while bcNOS was found to be more potent in the vaccinia system. Empirically, the tetracycline induced system gives us the ability to monitor ecNOS selectivity while the vaccinia system indicated the inhibitors to be very selective against ecNOS. The $\mathrm{IC}_{50}$ 's for iNOS in the A172 cells and the two 
selectivity assays differed, possibly due to differences in NO production between the different cell types. It was difficult to make a good correlation concerning the selectivity with the less active compounds as the maximum compound concentrations were $10 \mu \mathrm{M}$.

Our optimization strategy was to first modify the different parts of the template independently and then to combine the best substituents into a single compound that would have an improved overall profile. The template was partitioned into the amide $\left(R^{1}\right)$, piperazine substitution $\left(R^{2}\right)$, and pyrimidine substitution $\left(R^{3}\right)$ (Figure 2$)$. In addition, different attachment loci of the piperazine side chain, chain lengths, and alternatives to the piperazine were tested.

Modification of the group on the piperazine nitrogen resulted in a series that had only modest differences in potency and NOS selectivity (Table 1). Amides, amines, carbamates, ureas, and sulfonamides were well tolerated (e.g. 11a, 11b, 11d, 11e, and $11 \mathrm{f}$ respectively) with the unsubstituted compound, $\mathbf{1 1 g}$, as potent as any other compound. Steric bulk may have some effect on potency, with the large group, seen in 11i, being the least potent compound, but other compounds with large substituents, such as benzoyl (11q), and dansyl (11w), gave compounds with good activity. The basicity of the piperazine nitrogen did not seem to have much of an effect on activity in comparing $11 \mathrm{~b}$ vs. $11 \mathrm{c}, 11 \mathrm{~m}$ vs. $11 \mathrm{o}$, or $11 \mathrm{r}$ vs. $11 \mathrm{~s}$. Although the highly basic amidine $11 \mathrm{v}$ was less potent than the isosteric $11 \mathrm{a}$, the aminopyridine, 11t was highly active. Isosteric carbamates and ureas had similar activity (11d vs. 11e, 11j vs. 11p and 11k vs. 11q), as well as amides and sulfonamides (11a vs. 11f and 11c vs. 11I). In the 
vaccinia virus induced systems, these compounds demonstrated similar selectivity, good selectivity against ecNOS, and little selectivity against bcNOS.

Since we saw little effect of substituents on the piperazine nitrogen, we explored the effect of modulating ring size and replacement of the nitrogen (Figure 3). Incorporation of oxygen or carbon to give morpholine (13) or piperidine (12a) based systems gives highly potent compounds with similar activity to the piperazines (11). For faster synthetic access, the piperidines were utilized to explore subsequent modifications. The perhydroazepine (14) was also a highly potent compound.

Early in the optimization, we looked at the difference in activity between the three possible pyrimidine regioisomers (Table 2). Previous results from libraries had indicated a potency preference for the compounds with the imidazole in the 2 position of the pyrimidine and this was borne out. Comparison of the three regioisomers clearly shows that the 2-imidazolepyrimidine, $\mathbf{1 2} \mathbf{a}$, is the most potent. A possible explanation for this is that the imidazole needs to be nearly planar with the pyrimidine in the active site and this is the only regioisomer that has no hydrogens flanking the imidazole on the pyrimidine, allowing the imidazole to be more planar. This hypothesis was further supported by the relatively weak iNOS activity shown by $\mathbf{1 7}$, where the pyrimidine is replaced by a carbocyclic aromatic ring. In addition to trends in the SAR, the planar relationship of the imidazole and pyrimidine is demonstrated in the crystal structure (Figure 6). In the vaccinia virus induced systems, these compounds demonstrated 
similar overall selectivity, which can be described as good selectivity against ecNOS, and poor selectivity against bcNOS.

To examine the effect of side chain modifications, the corresponding piperidines, 12, were prepared (Table 3). Unlike the modifications on the piperazine, different side chains gave compounds with very different activity. The initial hits from the library showed a clear preference for oxygen containing substitution on an aromatic moiety and a specific chain length between the pyrimidine and the aromatic moiety. Placement of the methoxy group was important with a rank order of para, meta, and ortho $(\mathbf{1 2 b}>12 \mathrm{c}$ > 12d). The 3,4-disubstituted compound 12e has similar potency to the 4-substituted, 12b, but the 3,4,5-trisubstituted analog, 12f, lost significant potency. The potency difference between the isoelectronic $12 \mathrm{a}$ and $\mathbf{1 2 e}$ possibly indicates a steric interaction that is borne out in the crystal structure (Figure 6). Since the unsubstituted $\mathbf{1 2 g}$ lost a significant amount of activity and the 4-substituted compound $\mathbf{1 2 b}$ was the most potent monosubstituted compound, we further explored substituents at the 4- position, but found no better substituent. The sterically similar $12 \mathrm{~h}$ and $12 \mathrm{i}$ are potent, having activity less than $10 \mathrm{nM}$, but 12j-n were all much less active. Compounds with electron withdrawing groups, 120-r, were much less potent, but the sulfonamide $12 \mathrm{~s}$ has an $\mathrm{IC}_{50}$ of $17 \mathrm{nM}$. Some of the differences may be explained by a preference for a more electron rich aromatic moiety (12b vs. $\mathbf{1 2 j}$ and $\mathbf{1 2 k}$ vs. 12o), but the anilines (12l- $\mathbf{n})$ do not fit this pattern. The monocyclic heterocycles tested, $\mathbf{1 2 t}$ and $\mathbf{1 2 u}$ were less active than the unsubstituted $\mathbf{1 2 g}$. Substitution of the nitrogen (12v vs. $\mathbf{1 2 g}$ ) and benzylic position (12w vs. 12g) both decreased activity. Loss of the aromatic moiety as in the 
methylamide, 12x, gave a compound with little activity. In the vaccinia virus selectivity assays, the more active compounds $\left(\mathrm{IC}_{50}<20 \mathrm{nM}\right)$ demonstrated similar selectivity, good selectivity against ecNOS, and little selectivity against bcNOS.

Potency was very sensitive to the distance between the piperidine and the aromatic moiety (Table 3). Shortening the chain caused a dramatic decrease in activity, compare $12 \mathrm{a}$ with $12 \mathrm{z}$ or $12 \mathrm{e}$ with $12 \mathrm{aa}$. Lengthening the chain caused a modest decrease in activity, compare $12 \mathrm{e}$ with $\mathbf{1 2 b b}$ or $\mathbf{1 2 b}$ with $12 \mathrm{cc}$.

Substitution of the pyrimidine 6-position indicated a preference for smaller groups when comparing potency, although the trend between hydrogen and methyl substitution was inconsistent (Table 4, additional compounds were prepared in this series, but the trends are consistent with those shown). The phenyl (18b) and imidazole (18e) substituted pyrimidines were less active than the corresponding unsubstituted compound, 12a. The trifluoromethyl substituted analog $(\mathbf{1 8 d})$ had the worst activity, but the methyl analog (18c) was highly active. The difference in activity between the methyl and hydrogen substituted analogs were dependent on the amide substituent. When the benzodioxolane was the amide substituent, the hydrogen containing compound $\mathbf{1 2 a}$ was more potent than the methyl containing compound $\mathbf{1 8 c}$, but with other substituted benzyl amides, the hydrogen containing compound was the same or was less active than the methyl containing compound (data not shown). While the activity of 6chloropyrimidines was consistently high, as exemplified by $\mathbf{1 8 a}$, the potential for displacement of the chlorine from these analogues was a concern and the analogues 
were not pursued. The selectivity of the compounds was similar to those already discussed.

By screening secondary libraries, we found that the alternatively substituted piperazines, 19, had improved bcNOS selectivity, but somewhat decreased activity. Further studies bore out this observation. Analogues were prepared (Table 5), and although most of the SAR was similar to the initially prepared piperazines, differences did appear. Of the few amide analogues prepared, the benzodioxalanemethyl substituent was found to be the most active. Substitution of the 6-position of the pyrimidine showed a clear preference for either methyl or chloro (data not shown). Unlike the initially substituted piperazine, substitution of the 4-position of these analogs resulted in large differences in activity, depending on the substituent. The unsubstituted analog, 19a, was the least active among the analogs. The lower activity did not seem to be due to the basicity of the compound, because the methyl and benzyl substituted compounds (19b-c, respectively) were more active than the unsubstituted analog, but may be due to the ability of the side chain to have freedom to rotate over the piperazine. The isosteric sulfonamide $19 \mathrm{~d}$ and acetamide $19 \mathrm{e}$ have the same potency as $19 \mathrm{~b}$. In general, the different placement of the side chain had an effect on bcNOS selectivity. The isobutyramide 19f was the most active compound prepared in this series and the bcNOS selectivity in the vaccinia system was improved compared to the alternatively substituted piperazines, while the ecNOS selectivity remained the same. 
Two compounds were chosen for synthesis of their respective stereoisomers, 11d and 19f. The compounds were prepared by separating a common intermediate using chromatography on a chiral support, and continuing on to the final compound. A large difference was found in the activity of the two isomers (Table 6), with, as expected, the more active isomer having activity and selectivity similar to the mixture. The activity of the less active isomer should be interpreted with caution, as the analytical methods would not discern a small impurity $(<2 \%)$, which could easily explain all of the activity. The absolute stereochemistry of $\mathbf{1 1 d}$ was determined by X-ray crystallography of the compound in complex with the protein and is consistent with the stereochemistry of compounds prepared from d-proline (Table 7). The absolute stereochemistry of $\mathbf{1 9 d}$ is inferred from a related analog, for which a structure was obtained. ${ }^{17}$ Conveniently, the active isomers of $\mathbf{1 1 d}$ and $\mathbf{1 9 f}$ have different stereochemistry as they each arose from different isomers of starting material.

In order to avoid separating isomers, we tested commercially available starting materials that contained the desired stereocenter. Analogs of proline were prepared and found to be highly active, some showing unexpectedly high bcNOS selectivity (Table 7). Again, keeping the distance between the pyrimidine and benzodioxolane group to six atoms was important, as changes caused a significant decrease in activity (compounds not shown). Moving the amide function in the side chain had no effect on potency, but resulted in a change in selectivity for both isoforms (20 vs. 21). Having the amide adjacent to the pyrrolidine, $\mathbf{2 1}$, gave the most selective compounds identified in this series. The analogs arising from D-proline were significantly more potent than the 
analogs arising from L-proline and may better reflect the difference in activity of the stereoisomers (21b vs. $\mathbf{2 1} \mathbf{b}^{*}$ ) than the earlier described pairs.

We selected 21b for in vivo characterization due to its high potency and high selectivity versus the two other isoforms. The compound had good oral availability in both rats and dogs. In rats, the compound was dosed both intravenously and orally at $10 \mathrm{mg} / \mathrm{kg}$, and although the half-life after iv dosing was short $(0.7 \mathrm{~h})$, the clearance and oral availability were reasonable $(10 \mathrm{ml} / \mathrm{min} / \mathrm{kg}$ and $21 \%$, respectively, Figure $4 \mathrm{~A})$. The compound was administered to dogs at $3 \mathrm{mg} / \mathrm{kg}$ and the half-life after iv dosing was better $(2.5 \mathrm{~h})$, and the clearance and oral availability were improved $(4.5 \mathrm{ml} / \mathrm{min} / \mathrm{kg}$ and $71 \%$, respectively Figure 4B).

We then tested the ability of $\mathbf{2 1 b}$ to inhibit adjuvant-induced arthritis in a rat model. The compound was dosed subcutaneously at 3,10 , and $30 \mathrm{mg} / \mathrm{kg}$ twice a day and the rats were monitored and scored for arthritis using two methods, clinical signs and radiological scores (Figure 5). Compared to vehicle, both the 10 and $30 \mathrm{mg} / \mathrm{kg}$ dose resulted in a significantly lower clinical score. The $30 \mathrm{mg} / \mathrm{kg}$ dose also resulted in significantly lower radiological scores. For rats dosed with $30 \mathrm{mg} / \mathrm{kg}$, neither the clinical scores nor the radiological scores were significantly different from naïve animals by analysis of both methods and at least 6 of the ten animals in this high dose group were free of disease. No adverse effects were observed for any of the doses tested. 


\section{Structural Analysis}

An analysis of the structure of $\mathbf{2 1 b}$ bound to monomeric iNOS oxygenase domain explains much of the SAR previously described (Figure 6). ${ }^{18}$ The compound occupies the arginine binding pocket. The imidazole coordinates to the Fe, setting the inhibitors into the protein. The distal group of the piperazine $\left(R^{2}\right)$ would point into the solvent and consequently does not have much effect on the activity of the resulting compounds. The substituent off the amide points back towards the porphyrin and the benzodioxolane fills the pocket. The linker between the benzodioxolane and imidazole is critical, because sufficient flexibility and distance between the two groups is needed to accommodate the bend between the two aromatics, and the ability of the compound to bind to the enzyme. The saturated nitrogen heterocycle probably aides the bend by predisposing the molecule to a $\beta$-turn. We attempted to crystallize the less active enantiomer bound to the protein to better understand the binding, but the resulting crystals all contained the more potent isomer, which was presumably present as an undetected impurity (up to $2 \%$ would not be detected by our analytical methods).

A comparison of the inhibitor-monomer structure with a structure of the dimer helped rationalize the mechanism of inhibiting dimer formation seen with the compounds (Figure 7). The protein-protein interactions necessary for dimer formation are shown in Figure 7A. Compound 21b displaces helix 7a (red) side chains from the Arg binding site, and disrupts part of the dimer interface (Figure 7B), a disruption resulting in the disordering of the residues starting at helix $7 a$ and up to the proximal half of helix 8. 


\section{Conclusion}

A series of substituted pyrimidines containing an imidazole have been discovered that interrupts protein-protein interactions, displayed by inhibiting the dimerization of the iNOS monomers. This series has been optimized for their potency, selectivity against other NOS isoforms, and oral availability. Compound $\mathbf{2 1 \mathbf { b }}$ is a potent selective compound that shows efficacy in a model of rheumatoid arthritis. Future publications will illustrate the utilization of this template and the crystal structure in the design of novel templates.

\section{Experimental}

All starting materials not described below were purchased from commercial sources. All reagents and solvents were used as received from commercial sources without additional purification. Elemental analyses were performed by Robertson Microlit Laboratories; Madison, NJ and results were within $\pm 0.4 \%$ of the calculated values. NMR spectra were recorded with a Varian XL-300 spectrometer and were consistent with the assigned structures. Reverse phase HPLC were performed with a Rainin SD-1 Dynamax system and a C-18 reverse phase Dynamax 60A column using a gradient of acetonitrile $(0.1 \%$ TFA $)$ in water $(0.1 \%$ TFA).

6-Methyl-2-(methylthio)pyrimidin-4-one (5). To a solution of 4-hydroxy-2mercapto-6-methylpyrimidine (100 g, $0.70 \mathrm{~mol})$ in DMSO (1L) was added potassium carbonate (106 g, 0.77 moles), followed by iodomethane (48 mL, $0.77 \mathrm{~mol})$, and the mixture stirred at room temperature for $24 \mathrm{~h}$. The reaction mixture was poured into $4 \mathrm{~L}$ of 
water with stirring. The resulting solids were filtered and washed with water, acetonitrile, and ether to afford $79 \mathrm{~g}$ ( $72 \%$ yield) of a white solid.

4-Chloro-6-methyl-2-(methylthio)pyrimidine (6). To phosphorus oxychloride (300 mL) under nitrogen was added 6-methyl-2-methylthiopyrimidin-4-one (79 g, 0.51

mol), and the mixture was heated at $80^{\circ} \mathrm{C}$ for 5 hours. The reaction was concentrated under vacuum, the residue was poured onto $1 \mathrm{Kg}$ of ice, and extracted with dichloromethane. The extract was washed with saturated potassium carbonate, dried over basic alumina, charcoal treated, filtered, and concentrated under vacuum to give $81 \mathrm{~g}(91 \%$ yield $)$ of a pale yellow liquid. ${ }^{1} \mathrm{H}$ NMR $\left(\mathrm{CDCl}_{3}\right) \delta 6.8(\mathrm{~s}, 1 \mathrm{H}), 2.5(\mathrm{~s}, 3 \mathrm{H}), 2.4$ $(\mathrm{s}, 3 \mathrm{H})$.

4-Chloro-6-methyl-2-(methylsulfonyl)pyrimidine (7). A solution of 3chloroperoxybenzoic acid $(240 \mathrm{~g}, 77 \%, 0.97 \mathrm{~mol})$ in dichloromethane $(2.5 \mathrm{~L})$ was washed with saturated $\mathrm{NaCl}(500 \mathrm{~mL})$, dried over magnesium sulfate, transferred to a 3 $\mathrm{L}$ flask with mechanical stirring, and cooled to $-5^{\circ} \mathrm{C}$. A solution of 4-chloro-6-methyl-2(methylsulfonyl)pyrimidine $(81 \mathrm{~g}, 0.46 \mathrm{~mol})$ in $\mathrm{CH}_{2} \mathrm{Cl}_{2}(100 \mathrm{~mL})$ was added over 30 minutes. The reaction was allowed to warm to r.t. overnight. The solids filtered and washed with cold $\mathrm{CH}_{2} \mathrm{Cl}_{2}(500 \mathrm{~mL})$. The filtrate was washed with $10 \% \mathrm{~K}_{2} \mathrm{CO}_{3}(2 \mathrm{~L})$, dried over basic alumina, charcoal treated, filtered, and concentrated under vacuum. The residue was crystallized from hexanes $(1 \mathrm{~L})$ to afford $80 \mathrm{~g}$ ( $83 \%$ yield) of a white solid, which was stored under $\mathrm{N}_{2}$ at $0^{\circ} \mathrm{C} .{ }^{1} \mathrm{H}$ NMR $\left(\mathrm{CDCl}_{3}\right) \delta 7.45(\mathrm{~s}, 1 \mathrm{H}), 3.35(\mathrm{~s}, 3 \mathrm{H}), 2.65$ $(\mathrm{s}, 3 \mathrm{H})$.

Methyl 4-[(1,1-dimethylethoxy)carbonyl]-2-piperazineacetate (8). Methyl 1,4dibenzylpiperazine-2-acetate ${ }^{14}(26.8 \mathrm{~g}, 79 \mathrm{mmol})$ is dissolved in $\mathrm{MeOH}(500 \mathrm{~mL})$ and 
$0.5 \mathrm{~N} \mathrm{HCl}$ (aqueous, $400 \mathrm{~mL}, 0.2 \mathrm{~mol}) . \mathrm{Pd} / \mathrm{C}(10 \%, 9.5 \mathrm{~g})$ was added and the mixture was hydrogenated with $\mathrm{H}_{2}(50 \mathrm{psi})$ for 24 hours. The reaction was filtered through celite and the filtrate was concentrated in vacuo to remove most of the $\mathrm{MeOH}$. The residue was made basic with $\mathrm{K}_{2} \mathrm{CO}_{3}(\sim 16 \mathrm{~g})$ to $\mathrm{pH}=9-10$, and $\mathrm{THF}(300 \mathrm{~mL})$ was added. The reaction was cooled to $0^{\circ} \mathrm{C}$ and $\mathrm{BOC}-\mathrm{ON}(19.5 \mathrm{~g}, 79 \mathrm{mmol})$ dissolved in THF (100 mL) was added dropwise. The reaction was stirred at $0^{\circ}$ for 1 hour, allowed to warm up to room temperature, and stirred for 2 hours. Some solvent was removed in vacuo and the residue was extracted with ethyl acetate. The combined extracts were treated with $100 \mathrm{~mL}$ of $1 \mathrm{M} \mathrm{HCl}$ (aqueous). The aqueous layer was separated, washed with ethyl acetate, basified with $\mathrm{K}_{2} \mathrm{CO}_{3}$, and extracted with ethyl acetate. The combined organic layers were washed with brine, dried $\left(\mathrm{Na}_{2} \mathrm{SO}_{4}\right)$, and concentrated in vacuo to give 16.6

$\mathrm{g}(81 \%)$ of 8. ${ }^{1} \mathrm{H}$ NMR $\left(\mathrm{CDCl}_{3}\right) \delta 3.88(\mathrm{~b}, 2 \mathrm{H}), 3.75(\mathrm{~s}, 3 \mathrm{H}), 2.69-3.02(\mathrm{~m}, 4 \mathrm{H}), 2.55(\mathrm{~b}$, 1H), $2.37(\mathrm{dd}, 1 \mathrm{H}), 2.31(\mathrm{dd}, 1 \mathrm{H}), 1.4(\mathrm{~s}, 9 \mathrm{H})$.

\section{Methyl 1-[2-(1H-imidazol-1-yl)pyrimidin-4-yl]-4-[(1,1-}

\section{dimethylethoxy)carbonyl]-2-piperazineacetate (9). Methyl 4-[(1,1-}

dimethylethoxy)carbonyl]piperazine-2-acetate (8, $11.7 \mathrm{~g}, 45 \mathrm{mmol})$, 4-chloro-2-

methylsulfonylpyrimidine $(8.5 \mathrm{~g}, 44 \mathrm{mmol})$, and $\mathrm{K}_{2} \mathrm{CO}_{3}(13 \mathrm{~g}, 94 \mathrm{mmol})$ were dissolved in $\mathrm{CH}_{3} \mathrm{CN}(250 \mathrm{~mL})$ and heated to $35^{\circ} \mathrm{C}$ for $18 \mathrm{~h}$. Imidazole $(15 \mathrm{~g}, 220 \mathrm{mmol})$ was added ant the reaction was heated to $65^{\circ} \mathrm{C}$ for $24 \mathrm{~h}$. The solvent was removed in vacuo, and the residue was slurried in $\mathrm{CH}_{2} \mathrm{Cl}_{2}$ and washed with water. The organic layer was separated, dried $\left(\mathrm{MgSO}_{4}\right)$, and concentrated in vacuo. The residue was chromatographed on silica ( $3 \% \mathrm{MeOH} / \mathrm{CH}_{2} \mathrm{Cl}_{2}$ ) to give $14.5 \mathrm{~g}(82 \%)$ of 9 .

\section{N-[(1,3-benzodioxol-5-yl)methyl]-1-[2-(1H-imidazol-1-yl)pyrimidin-4-yl]-4-}


[(1,1-dimethylethoxy)carbonyl]-2-piperazineacetamide (10). To methyl 1-[2-(1Himidazol-1-yl)pyrimidin-4-yl]-4-[(1,1-dimethylethoxy)carbonyl]piperazine-2-acetate (14.5 $\mathrm{g}, 36 \mathrm{mmol})$ dissolved in THF $(250 \mathrm{~mL})$ and water $(70 \mathrm{~mL})$ was added lithium hydroxide hydrate $(7 \mathrm{~g}, 0.16 \mathrm{~mol})$. The reaction was stirred for $18 \mathrm{~h}$ and some of the solvent was removed in vacuo. Water $(200 \mathrm{~mL})$ was added and the material was washed with ether. The aqueous solution was acidified with acetic acid and the resulting precipitate was collected by filtration and washed with water, $\mathrm{CH}_{3} \mathrm{CN}$, and ether to give $10 \mathrm{~g}$ of a white solid. The solid was suspended in DMF (100 mL) and carbonyldiimidazole $(4.4 \mathrm{~g}, 27$ mmol) was added. The reaction was stirred for $3 \mathrm{~h}$ and became homogeneous.

Piperonylamine $(3.5 \mathrm{~mL}, 28 \mathrm{mmol})$ was added and the reaction was stirred for another 1 h. The mixture was poured into $0.1 \mathrm{~N} \mathrm{KOH}$ and extracted with $\mathrm{CH}_{2} \mathrm{Cl}_{2}$. The extract was washed with water, dried $\left(\mathrm{MgSO}_{4}\right)$, and the solvent was removed in vacuo to give $13 \mathrm{~g}$ (69\%) of (10) as a colorless oil.

4-(acetyl)-N-[(1,3-benzodioxol-5-yl)methyl]-1-[2-(1H-imidazol-1-yl)pyrimidin4-yl]- 2-piperazineacetamide (11a). NMR (DMSO-d 6 ) $\delta 8.5$ (s, 1 H), 8.35 (br, 1 H), 8.2 (m, $1 \mathrm{H}), 7.85(\mathrm{~s}, 1 \mathrm{H}), 7.03(\mathrm{~s}, 1 \mathrm{H}), 6.6(\mathrm{~m}, 4 \mathrm{H}), 5.9(\mathrm{~s}, 2 \mathrm{H}), 5.3(\mathrm{br}, 1 \mathrm{H}), 4.6(\mathrm{br}, 1$ H), $4.25(\mathrm{~m}, 1 \mathrm{H}), 4.1(\mathrm{~m}, 2 \mathrm{H}), 3.8(\mathrm{~m}, 1 \mathrm{H}), 3.4(\mathrm{~m}, 2 \mathrm{H}), 3.0(\mathrm{~m}, 1 \mathrm{H}), 2.5(\mathrm{~m}, 2 \mathrm{H})$, 1.95 and $2.05(2 \mathrm{~s}, 3 \mathrm{H})$. Anal. $\left(\mathrm{C}_{23} \mathrm{H}_{25} \mathrm{~N}_{7} \mathrm{O}_{4} .0 .3 \mathrm{H}_{2} \mathrm{O}\right) \mathrm{C}, \mathrm{H}, \mathrm{N}$.

$N$-[(1,3-benzodioxol-5-yl)methyl]-1-[2-(1H-imidazol-1-yl)pyrimidin-4-yl]-4(phenylmethyl)-2-piperazineacetamide (11b). NMR (DMSO-d $\left.\mathrm{d}_{6}\right) \delta 8.5(\mathrm{~s}, 1 \mathrm{H}), 8.4(\mathrm{br}$, $1 \mathrm{H}), 8.2(\mathrm{~d}, 1 \mathrm{H}), 7.85(\mathrm{~s}, 1 \mathrm{H}), 7.3(\mathrm{~m}, 5 \mathrm{H}), 7.03(\mathrm{~s}, 1 \mathrm{H}), 6.8(\mathrm{~m}, 3 \mathrm{H}), 6.5(\mathrm{~d}, 1 \mathrm{H}), 5.9$ (s, 2 H), 5.3 (br, 1 H), $4.6(b r, 1 \mathrm{H}), 4.1(\mathrm{~m}, 2 \mathrm{H}), 3.95(\mathrm{dd}, 1 \mathrm{H}), 355(\mathrm{~d}, 1 \mathrm{H}), 3.45$ (d, 1 H), $2.9(\mathrm{~d}, 1 \mathrm{H}), 2.75(\mathrm{~d}, 1 \mathrm{H}), 2.7(\mathrm{br}, 1 \mathrm{H}), 2.1(\mathrm{~m}, 2 \mathrm{H})$. Anal. $\left(\mathrm{C}_{28} \mathrm{H}_{29} \mathrm{~N}_{7} \mathrm{O}_{3}\right) \mathrm{C}, \mathrm{H}, \mathrm{N}$. 
$N$-[(1,3-benzodioxol-5-yl)methyl]-1-[2-(1H-imidazol-1-yl)pyrimidin-4-yl]-4(phenylcarbonyl)-2-piperazineacetamide (11c). NMR (DMSO-d 6 ) $\delta 8.45(\mathrm{~s}, 1 \mathrm{H}), 8.2$ (d, 1 H), 7.95 (br, 1 H), 7.85 (s, 1 H), $7.45(\mathrm{~s}, 5 \mathrm{H}), 7.03(\mathrm{~s}, 1 \mathrm{H}), 6.7(\mathrm{~m}, 4 \mathrm{H}), 5.9(\mathrm{~s}, 2$ H), $5.0(\mathrm{~m}, 1 \mathrm{H}), 4.3(\mathrm{~d}, 1 \mathrm{H}), 4.1(\mathrm{~m}, 4 \mathrm{H}), 3.4(\mathrm{~m}, 2 \mathrm{H}), 3.3(\mathrm{~m}, 1 \mathrm{H}), 2.6(\mathrm{~m}, 2 \mathrm{H})$. Anal. $\left(\mathrm{C}_{28} \mathrm{H}_{27} \mathrm{~N}_{7} \mathrm{O}_{4}\right) \mathrm{C}, \mathrm{H}, \mathrm{N}$.

N-[(1,3-benzodioxol-5-yl)methyl]-1-[2-(1H-imidazol-1-yl)pyrimidin-4-yl]-4[(methoxy)carbonyl]-2-piperazineacetamide (11d). Compound $11 \mathrm{~g}(5.04 \mathrm{~g}, 12 \mathrm{mmol})$ was slurried in $\mathrm{CH}_{2} \mathrm{Cl}_{2}(100 \mathrm{~mL})$. Methyl chloroformate $(1.03 \mathrm{~mL}, 13 \mathrm{mmol})$ and $1 \mathrm{~N}$ $\mathrm{NaOH}(12.5 \mathrm{~mL})$ was added and the reaction stirred vigorously overnight. The clear solutions were separated and the organic layer was dried $\left(\mathrm{Na}_{2} \mathrm{SO}_{4}\right)$ and the solvent removed in vacuo. The residue was chromatographed $\left(5 \% \mathrm{MeOH}\right.$ in $\left.\mathrm{CH}_{2} \mathrm{Cl}_{2}\right)$ to give $5.19 \mathrm{~g}(90 \%) . \quad$ NMR (DMSO-d $) \delta 8.45(\mathrm{~s}, 1 \mathrm{H}), 8.2(\mathrm{~d}, 1 \mathrm{H}), 8.0(\mathrm{br}, 1 \mathrm{H}), 7.85(\mathrm{~s}, 1 \mathrm{H})$, 7.03 (s, 1 H), 6.7 (m, 4 H), 5.9 (s, 2 H), 4.95 (br, 1 H), 4.15 (d, 1 H), 4.15 (d, 2 H), 3.95 (d, $2 \mathrm{H}), 3.65(\mathrm{~s}, 3 \mathrm{H}), 3.3(\mathrm{~m}, 2 \mathrm{H}), 3.15(\mathrm{dd}, 1 \mathrm{H}), 2.5(\mathrm{~m}, 2 \mathrm{H})$. Anal. $\left(\mathrm{C}_{23} \mathrm{H}_{25} \mathrm{~N}_{7} \mathrm{O}_{5}\right) \mathrm{C}$, $\mathrm{H}, \mathrm{N}$.

$N$-[(1,3-benzodioxol-5-yl)methyl]-1-[2-(1H-imidazol-1-yl)pyrimidin-4-yl]-4[(methylamino)carbonyl]-2-piperazineacetamide (11e). NMR (DMSO-d $\left.\mathrm{d}_{6}\right) \delta 8.45$ (s, 1 H), $8.2(\mathrm{~d}, 1 \mathrm{H}), 8.0(\mathrm{br}, 1 \mathrm{H}), 7.8(\mathrm{~s}, 1 \mathrm{H}), 7.03(\mathrm{~s}, 1 \mathrm{H}), 6.7(\mathrm{~m}, 4 \mathrm{H}), 6.15(\mathrm{br}, 1 \mathrm{H}), 5.9$ (s, $2 \mathrm{H}), 4.9(\mathrm{br}, 1 \mathrm{H}), 4.2(\mathrm{~m}, 3 \mathrm{H}), 3.9(\mathrm{~d}, 2 \mathrm{H}), 3.25(\mathrm{dt}, 1 \mathrm{H}), 3.1(\mathrm{dd}, 1 \mathrm{H}), 3.0(\mathrm{~m}, 1 \mathrm{H})$, $2.6(\mathrm{~s}, 3 \mathrm{H}), 2.5$ (m, $2 \mathrm{H})$. Anal. $\left(\mathrm{C}_{23} \mathrm{H}_{26} \mathrm{~N}_{8} \mathrm{O}_{4} .0 .5 \mathrm{H}_{2} \mathrm{O}\right) \mathrm{C}, \mathrm{H}, \mathrm{N}$.

\section{N-[(1,3-benzodioxol-5-yl)methyl]-1-[2-(1H-imidazol-1-yl)pyrimidin-4-yl]-4-} (methylsulfonyl)-2-piperazineacetamide (11f). NMR (DMSO-d $\left.\mathrm{d}_{6}\right) \delta 8.45(\mathrm{~s}, 1 \mathrm{H}), 8.2$ (d, $1 \mathrm{H}), 8.0(\mathrm{br}, 1 \mathrm{H}), 7.8(\mathrm{~s}, 1 \mathrm{H}), 7.03(\mathrm{~s}, 1 \mathrm{H}), 6.7(\mathrm{~m}, 4 \mathrm{H}), 5.85(\mathrm{~s}, 2 \mathrm{H}), 5.1(\mathrm{br}, 1 \mathrm{H})$, 
$4.45(\mathrm{~d}, 1 \mathrm{H}), 4.1(\mathrm{~m}, 2 \mathrm{H}), 3.6(\mathrm{~m}, 2 \mathrm{H}), 3.3(\mathrm{dt}, 1 \mathrm{H}), 3.05(\mathrm{dd}, 1 \mathrm{H}), 2.9(\mathrm{~m}, 1 \mathrm{H}), 2.9(\mathrm{~s}$, $3 \mathrm{H}), 2.65(\mathrm{~d}, 2 \mathrm{H})$. Anal. $\left(\mathrm{C}_{22} \mathrm{H}_{25} \mathrm{~N}_{7} \mathrm{O}_{5} \mathrm{~S} \cdot 0.25 \mathrm{CH}_{2} \mathrm{Cl}_{2}\right) \mathrm{C}, \mathrm{H}, \mathrm{N}$.

$N$-[(1,3-benzodioxol-5-yl)methyl]-1-[2-(1H-imidazol-1-yl)pyrimidin-4-yl]-2piperazineacetamide (11g). $N$-[(1,3-benzodioxol-5-yl)methyl]-1-[2-(1H-imidazol-1yl)pyrimidin-4-yl]-4-[(1,1-dimethylethoxy)carbonyl]piperazine-2-acetamide (13 g, 24 mmol) was dissolved in $\mathrm{CH}_{2} \mathrm{Cl}_{2}(200 \mathrm{~mL})$ and cooled to $0^{\circ} \mathrm{C}$. Trifluoroacetic acid (100 $\mathrm{mL}$ ) was added and the reaction was allowed to warm to room temperature. The solvent was removed in vacuo and the residue dissolved in EtOAc $(200 \mathrm{~mL})$. The organic layer was washed with sat. $\mathrm{K}_{2} \mathrm{CO}_{3}$, dried $\left(\mathrm{MgSO}_{4}\right)$, and the solvent removed in vacuo. Crystallization from ether gave $6 \mathrm{~g}(57 \%)$ of a white solid. $\mathrm{mp} 160-162{ }^{\circ} \mathrm{C}$. $\operatorname{NMR}\left(\mathrm{CDCl}_{3}\right) \delta 8.5(\mathrm{~s}, 1 \mathrm{H}), 8.18(\mathrm{~d}, 1 \mathrm{H}), 7.8(\mathrm{~s}, 1 \mathrm{H}), 7.1(\mathrm{~s}, 1 \mathrm{H}), 6.7(\mathrm{~m}, 3 \mathrm{H}), 6.55$ (m, 1H), $6.2(\mathrm{t}, 1 \mathrm{H}), 5.9(\mathrm{~s}, 2 \mathrm{H}), 4.8(\mathrm{br}, 1 \mathrm{H}), 4.3(\mathrm{~m}, 2 \mathrm{H}), 2.8-3.2(\mathrm{~m}, 7 \mathrm{H}), 2.55(\mathrm{dd}, 1$ H). Anal. $\left(\mathrm{C}_{21} \mathrm{H}_{23} \mathrm{~N}_{7} \mathrm{O}_{3} \cdot 0.3 \mathrm{H}_{2} \mathrm{O}\right) \mathrm{C}, \mathrm{H}, \mathrm{N}$.

N-[(1,3-benzodioxol-5-yl)methyl]-1-[2-(1H-imidazol-1-yl)pyrimidin-4-yl]-4methyl-2-piperazineacetamide (11h). NMR $\left(\mathrm{CDCl}_{3}\right) \delta 8.45(\mathrm{~s}, 1 \mathrm{H}), 8.15(\mathrm{~d}, 1 \mathrm{H}), 7.78$ (s, $1 \mathrm{H}), 7.03(\mathrm{~s}, 1 \mathrm{H}), 6.4-6.7(\mathrm{~m}, 4 \mathrm{H}), 5.85(\mathrm{~s}, 2 \mathrm{H}), 4.25(\mathrm{~m}, 2 \mathrm{H}), 3.1(\mathrm{~m}, 1 \mathrm{H}), 2.8(\mathrm{~m}$, $4 \mathrm{H}), 2.5(\mathrm{dd}, 1 \mathrm{H}), 2.25(\mathrm{~s}, 3 \mathrm{H}), 2.2(\mathrm{~m}, 1 \mathrm{H}), 2.05(\mathrm{t}, 1 \mathrm{H})$. Anal. $\left(\mathrm{C}_{22} \mathrm{H}_{26} \mathrm{~N}_{7} \mathrm{O}_{3} \cdot 0.2\right.$ $\left.\mathrm{CH}_{2} \mathrm{Cl}_{2}\right) \mathrm{C}, \mathrm{H}, \mathrm{N}$.

N-[(1,3-benzodioxol-5-yl)methyl]-1-[2-(1H-imidazol-1-yl)pyrimidin-4-yl]-4-[(1naphthylenyl)methyl]-2-piperazineacetamide (11i). NMR $\left(\mathrm{CDCl}_{3}\right) \delta 8.55(\mathrm{~s}, 1 \mathrm{H})$, $8.45(\mathrm{~s}, 1 \mathrm{H}), 8.15(\mathrm{~d}, 1 \mathrm{H}), 7.8(\mathrm{~m}, 3 \mathrm{H}), 7.4(\mathrm{~m}, 4 \mathrm{H}), 7.1(\mathrm{~s}, 1 \mathrm{H}), 6.65(\mathrm{~d}, 1 \mathrm{H}), 6.55$ (m, 1H), $6.4(\mathrm{~m}, 2 \mathrm{H}), 5.9(\mathrm{~s}, 2 \mathrm{H}), 4.6(\mathrm{~m}, 1 \mathrm{H}), 4.3(\mathrm{~m}, 2 \mathrm{H}), 4.0(\mathrm{dd}, 1 \mathrm{H}), 3.65(\mathrm{~m}, 1 \mathrm{H})$, 
$3.1(\mathrm{~m}, 3 \mathrm{H}), 2.65(\mathrm{~m}, 2 \mathrm{H}), 2.4(\mathrm{t}, 1 \mathrm{H}), 2.1(\mathrm{~m}, 2 \mathrm{H})$. Anal. $\left(\mathrm{C}_{32} \mathrm{H}_{31} \mathrm{~N}_{7} \mathrm{O}_{3} \cdot \mathrm{HCl} .0 .3 \mathrm{H}_{2} \mathrm{O}\right) \mathrm{C}$, $\mathrm{H}, \mathrm{N}$.

N-(1,3-benzodioxol-5-ylmethyl)-1-[2-(1H-imidazol-yl)-4-pyrimidinyl]-4(phenylamino)carbonyl]-2-piperazineacetamide (11j) $1 \mathrm{H} \mathrm{NMR}\left(\mathrm{CDCl}_{3}\right)$ $\delta 8.25(\mathrm{~m}, 1 \mathrm{H}), 8.20(\mathrm{~m}, 1 \mathrm{H}), 7.80(\mathrm{~m}, 1 \mathrm{H}), 7.50(\mathrm{~m}, 2 \mathrm{H}), 7.30(\mathrm{~m}, 2 \mathrm{H}), 7.00(\mathrm{~m}, 1 \mathrm{H})$, $6.80(\mathrm{~m}, 4 \mathrm{H}), 6.40(\mathrm{~d}, 1 \mathrm{H}), 5.80(\mathrm{~s}, 2 \mathrm{H}), 5.0(\mathrm{~m}, 1 \mathrm{H}), 4.35-4.65(\mathrm{~m}, 4 \mathrm{H}), 3.60(\mathrm{~m}$, 1H), $3.30(\mathrm{~m}, 1 \mathrm{H}), 3.20(\mathrm{~m}, 1 \mathrm{H}), 3.00(\mathrm{~m}, 1 \mathrm{H}), 2.80(\mathrm{~m}, 1 \mathrm{H}), 2.30(\mathrm{~d}, 1 \mathrm{H}), 1.80(\mathrm{~m}, 2 \mathrm{H})$. Anal. $\left(\mathrm{C}_{28} \mathrm{H}_{28} \mathrm{~N}_{8} \mathrm{O}_{4} \cdot 0.5 \mathrm{H}_{2} \mathrm{O}\right) \mathrm{C}, \mathrm{H}, \mathrm{N}$.

N-(1,3-benzodioxol-5-ylmethyl)-1-[2-(1H-imidazol-yl)-4-pyrimidinyl]-4[[(phenylmethyl)amino]carbonyl]-2-piperazineacetamide (11k). $1 \mathrm{H} \mathrm{NMR}\left(\mathrm{CDCl}_{3}\right)$

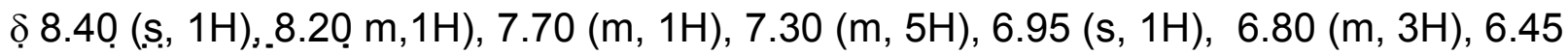
(m, 1H), $5.90(\mathrm{~s}, 2 \mathrm{H}), 4.20-4.50(\mathrm{~m}, 8 \mathrm{H}), 3.20(\mathrm{~m}, 3 \mathrm{H}), 2.70(\mathrm{~m}, 1 \mathrm{H}), 2.20(\mathrm{~m}, 1 \mathrm{H}), 1.90$ (m, 2H). Anal. $\left(\mathrm{C}_{29} \mathrm{H}_{30} \mathrm{~N}_{8} \mathrm{O}_{4} \cdot 0.8 \mathrm{H}_{2} \mathrm{O}\right) \mathrm{C}, \mathrm{H}, \mathrm{N}$.

\section{N-(1,3-benzodioxol-5-ylmethyl)-1-[2-(1H-imidazol-yl)-4-pyrimidinyl]-4-}

(phenylsulfonyl)-2-piperazineacetamide (11)). 1H NMR (CDCl 3$) \delta 8.50$ (s. $1 \mathrm{H})$ ), 8.20 d, $1 \mathrm{H}), 7.50-7.80(\mathrm{~m}, 6 \mathrm{H}), 7.00(\mathrm{~m}, 1 \mathrm{H}), 6.70(\mathrm{~m}, 3 \mathrm{H}), 6.50(\mathrm{~m}, 2 \mathrm{H}), 5.90(\mathrm{~s}, 2 \mathrm{H}), 4.30$ (m, 2H), $3.90(\mathrm{~m}, 1 \mathrm{H}), 3.70(\mathrm{~m}, 1 \mathrm{H}), 3.20(\mathrm{~m}, 1 \mathrm{H}), 2.95(\mathrm{~m}, 1 \mathrm{H}), 2.50(\mathrm{~m}, 3 \mathrm{H}), 2.0(\mathrm{~m}$, 2H). Anal. $\left(\mathrm{C}_{27} \mathrm{H}_{27} \mathrm{~N}_{7} \mathrm{O}_{5} \mathrm{~S} .0 .7 \mathrm{H}_{2} \mathrm{O}\right) \mathrm{C}, \mathrm{H}, \mathrm{N}$.

N-[(1,3-benzodioxol-5-yl)methyl]-1-[2-(1H-imidazol-1-yl)pyrimidin-4-yl]-4-(2furylmethyl)-2-piperazineacetamide (11m). NMR $\left(\mathrm{CDCl}_{3}\right) \delta 8.45(\mathrm{~s}, 1 \mathrm{H}), 8.1(\mathrm{~d}, 1 \mathrm{H})$, $7.78(\mathrm{~s}, 1 \mathrm{H}), 7.35(\mathrm{~s}, 1 \mathrm{H}), 7.03(\mathrm{~s}, 1 \mathrm{H}), 6.6(\mathrm{~m}, 4 \mathrm{H}), 6.3(\mathrm{~s}, 1 \mathrm{H}), 6.2(\mathrm{~s}, 1 \mathrm{H}), 5.85(\mathrm{~s}$, $2 \mathrm{H}), 4.6$ (br, $1 \mathrm{H}), 4.25(\mathrm{dd}, 1 \mathrm{H}), 4.15(\mathrm{dd}, 1 \mathrm{H}), 4.0(\mathrm{~m}, 2 \mathrm{H}), 3.55(\mathrm{AB}, 2 \mathrm{H}), 3.15(\mathrm{~m}, 1$ H), $2.8(\mathrm{~m}, 3 \mathrm{H}), 2.55(\mathrm{dd}, 1 \mathrm{H}), 2.2(\mathrm{~m}, 2 \mathrm{H})$. Anal. $\left(\mathrm{C}_{26} \mathrm{H}_{27} \mathrm{~N}_{7} \mathrm{O}_{4} .0 .7 \mathrm{H}_{2} \mathrm{O}\right) \mathrm{C}, \mathrm{H}, \mathrm{N}$. 
N-[(1,3-benzodioxol-5-yl)methyl]-1-[2-(1H-imidazol-1-yl)pyrimidin-4-yl]-4(methylsulfonyl)-2-piperazineacetamide (11n). NMR (DMSO-d $\left.\mathrm{d}_{6}\right) \delta 8.45$ (s, $\left.1 \mathrm{H}\right), 8.2$ (d, $1 \mathrm{H}), 7.9(\mathrm{br}, 1 \mathrm{H}), 7.83(\mathrm{~s}, 1 \mathrm{H}), 7.35(\mathrm{~m}, 4 \mathrm{H}), 7.3(\mathrm{~m}, 1 \mathrm{H}), 7.03(\mathrm{~s}, 1 \mathrm{H}), 6.7(\mathrm{~m}, 4$ H), $5.9(\mathrm{~s}, 2 \mathrm{H}), 4.95(\mathrm{~m}, 1 \mathrm{H}), 4.6(\mathrm{~s}, 2 \mathrm{H}), 4.25(\mathrm{~m}, 4 \mathrm{H}), 4.15(\mathrm{~m}, 3 \mathrm{H}), 3.35(\mathrm{~m}, 2 \mathrm{H})$, $3.2(\mathrm{~m}, 1 \mathrm{H}), 2.55(\mathrm{~m}, 2 \mathrm{H})$. Anal. $\left(\mathrm{C}_{30} \mathrm{H}_{31} \mathrm{~N}_{7} \mathrm{O}_{5} .0 .5 \mathrm{H}_{2} \mathrm{O}\right) \mathrm{C}, \mathrm{H}, \mathrm{N}$.

N-(1,3-benzodioxol-5-ylmethyl)-4-(2-furanylcarbonyl)-1-[2-(1H-imidazol-yl)-4pyrimidinyl]-2-piperazineacetamide (110). 1H NMR $\left(\mathrm{CDCl}_{3}\right) \delta 8.50(\mathrm{~m}, 1 \mathrm{H}), 8.20(\mathrm{~m}$, 1H), $7.80(\mathrm{~m}, 1 \mathrm{H}), 7.50(\mathrm{~m}, 1 \mathrm{H}), 7.00(\mathrm{~m}, 2 \mathrm{H}), 6.70(\mathrm{~m}, 4 \mathrm{H}), 6.50(\mathrm{~m}, 1 \mathrm{H}), 5.90(\mathrm{~s}, 2 \mathrm{H})$, $4.50(\mathrm{~m}, 2 \mathrm{H}), 4.30(\mathrm{~m}, 2 \mathrm{H}), 3.20(\mathrm{~m}, 4 \mathrm{H}), 2.70(\mathrm{~m}, 1 \mathrm{H}), 2.40(\mathrm{~m}, 1 \mathrm{H}), 2.05(\mathrm{~m}, 2 \mathrm{H})$. Anal. $\left(\mathrm{C}_{28} \mathrm{H}_{25} \mathrm{~N}_{7} \mathrm{O}_{5} \cdot 0.2 \mathrm{CH}_{2} \mathrm{Cl}_{2}\right) \mathrm{C}, \mathrm{H}, \mathrm{N}$.

3-[2-[(1,3- -benzodioxol-5-ylmethyl)amino]-2-oxoethyl]-4-[2-(1H-imidazol-yl)4-pyrimidinyl]-1-piperazinecarboxylic acid, phenylester (11p). $1 \mathrm{H} \mathrm{NMR}\left(\mathrm{CDCl}_{3}\right)$ $8.50(\mathrm{~m}, 1 \mathrm{H}), 8.20(\mathrm{~m}, 1 \mathrm{H}), 7.80(\mathrm{~m}, 1 \mathrm{H}), 7.35(\mathrm{~m}, 1 \mathrm{H}), 7.20(\mathrm{~m}, 1 \mathrm{H}), 7.10(\mathrm{~m}, 4 \mathrm{H}), 6.60$ (m, 5H), $5.85(\mathrm{~s}, 2 \mathrm{H}), 4.30(\mathrm{~m}, 4 \mathrm{H}), 3.30(\mathrm{~m}, 3 \mathrm{H}), 2.50(\mathrm{~m}, 2 \mathrm{H}), 2.00(\mathrm{~m}, 2 \mathrm{H})$. Anal. $\left(\mathrm{C}_{28} \mathrm{H}_{27} \mathrm{~N}_{7} \mathrm{O}_{5} \cdot 0.1 \mathrm{CH}_{2} \mathrm{Cl}_{2}\right) \mathrm{C}, \mathrm{H}, \mathrm{N}$.

$N$-[(1,3-benzodioxol-5-yl)methyl]-1-[2-(1H-imidazol-1-yl)pyrimidin-4-yl]-4[(phenylmethoxy)carbonyl]piperazine-2-acetamide (11q). NMR $\left(\mathrm{CDCl}_{3}\right) \delta 8.45(\mathrm{~s}, 1$ H), $8.2(\mathrm{~d}, 1 \mathrm{H}), 7.8(\mathrm{~s}, 1 \mathrm{H}), 7.35(\mathrm{~m}, 5 \mathrm{H}), 7.05(\mathrm{~s}, 1 \mathrm{H}), 6.6(\mathrm{~m}, 4 \mathrm{H}), 5.85(\mathrm{~s}, 2 \mathrm{H}), 5.15$ (m, $2 \mathrm{H}), 4.2(\mathrm{~m}, 5 \mathrm{H}), 3.1(\mathrm{~m}, 3 \mathrm{H}), 2.5(\mathrm{~m}, 2 \mathrm{H}), 2.0(\mathrm{~m}, 1 \mathrm{H})$. Anal.

$\left(\mathrm{C}_{29} \mathrm{H}_{29} \mathrm{~N}_{7} \mathrm{O}_{5} \cdot 0.5 \mathrm{H}_{2} \mathrm{O}\right) \mathrm{C}, \mathrm{H}, \mathrm{N}$.

N-[(1,3-benzodioxol-5-yl)methyl]-1-[2-(1H-imidazol-1-yl)pyrimidin-4-yl]-4-(3methylbutyl)-2-piperazineacetamide (11r). NMR $\left(\mathrm{CDCl}_{3}\right) \delta 8.5(\mathrm{~s}, 1 \mathrm{H}), 8.15(\mathrm{~d}, 1 \mathrm{H})$, $7.8(\mathrm{~s}, 1 \mathrm{H}), 7.05(\mathrm{~s}, 1 \mathrm{H}), 6.65(\mathrm{~m}, 3 \mathrm{H}), 6.5(\mathrm{~m}, 1 \mathrm{H}), 6.25(\mathrm{~m}, 1 \mathrm{H}), 5.9(\mathrm{~s}, 2 \mathrm{H}), 4.7(\mathrm{br}$, 
$1 \mathrm{H}), 4.25(\mathrm{~m}, 2 \mathrm{H}), 3.15(\mathrm{~m}, 1 \mathrm{H}), 2.85(\mathrm{~m}, 3 \mathrm{H}), 2.5(\mathrm{dd}, 1 \mathrm{H}), 2.3(\mathrm{~m}, 2 \mathrm{H}), 2.1(\mathrm{~m}, 3$

H), $1.6(\mathrm{~m}, 1 \mathrm{H}), 1.3(\mathrm{~m}, 2 \mathrm{H}), 0.9(\mathrm{~m}, 6 \mathrm{H})$. Anal. $\left(\mathrm{C}_{26} \mathrm{H}_{33} \mathrm{~N}_{7} \mathrm{O}_{3} .0 .5 \mathrm{H}_{2} \mathrm{O}\right) \mathrm{C}, \mathrm{H}, \mathrm{N}$.

3-[2-[(1,3- -benzodioxol-5-ylmethyl)amino]-2-oxoethyl]-4-[2-(1H-imidazol-yl)4-pyrimidinyl]-1-piperazinecarboxylic acid,1- methylethylester (11s). 1H NMR $\left(\mathrm{CDCl}_{3}\right) \delta 8.5(\mathrm{~s}, 1 \mathrm{H}), 8.2(\mathrm{~m}, 1 \mathrm{H}), 7.80(\mathrm{~m}, 1 \mathrm{H}), 7.05(\mathrm{~m}, 1 \mathrm{H}), 6.90(\mathrm{~m}, 1 \mathrm{H}), 6.60(\mathrm{~m}$, 4H), $5.90(\mathrm{~s}, 2 \mathrm{H}), 5.00(\mathrm{~m}, 2 \mathrm{H}), 4.40(\mathrm{~m}, 1 \mathrm{H}), 4.20(\mathrm{~m}, 3 \mathrm{H}), 3.10(\mathrm{~m}, 2 \mathrm{H}), 2.60(\mathrm{~m}, 1 \mathrm{H})$, $2.40(\mathrm{~m}, 1 \mathrm{H}), 1.95(\mathrm{~s}, 2 \mathrm{H}), 1.30(\mathrm{~m}, 6 \mathrm{H})$. Anal. $\left(\mathrm{C}_{25} \mathrm{H}_{29} \mathrm{~N}_{7} \mathrm{O}_{5} .0 .5 \mathrm{H}_{2} \mathrm{O}\right) \mathrm{C}, \mathrm{H}, \mathrm{N}$.

$N$-[(1,3-benzodioxol-5-yl)methyl]-1-[2-(1H-imidazol-1-yl)pyrimidin-4-yl]-4-(6fluoropyridin-2-yl)-2-piperazineacetamide (11t). NMR (DMSO-d 6 ) $\delta 8.5(\mathrm{~s}, 1 \mathrm{H}), 8.4$ (m, $1 \mathrm{H}), 8.2(\mathrm{~d}, 1 \mathrm{H}), 7.9(\mathrm{~s}, 1 \mathrm{H}), 7.65(\mathrm{~m}, 1 \mathrm{H}), 7.05(\mathrm{~s}, 1 \mathrm{H}), 6.75(\mathrm{~d}, 1 \mathrm{H}), 6.7(\mathrm{~m}, 2$ H), $6.6(\mathrm{~m}, 1 \mathrm{H}), 6.3(\mathrm{~m}, 1 \mathrm{H}), 5.9(\mathrm{~s}, 2 \mathrm{H}), 4.0(\mathrm{~m}, 3 \mathrm{H}), 3.3(\mathrm{~m}, 4 \mathrm{H})$. Anal. $\left(\mathrm{C}_{26} \mathrm{H}_{25} \mathrm{~N}_{8} \mathrm{O}_{3} \mathrm{~F} .0 .5 \mathrm{H}_{2} \mathrm{O}\right) \mathrm{C}, \mathrm{H}, \mathrm{N}$.

N-[(1,3-benzodioxol-5-yl)methyl]-1-[2-(1H-imidazol-1-yl)pyrimidin-4-yl]-4-(2furylmethyl)-2-piperazineacetamide (11u). NMR (DMSO-d $\left.\mathrm{d}_{6}\right) \delta 8.45(\mathrm{~s}, 1 \mathrm{H}), 8.35$ (br, $1 \mathrm{H}), 8.15(\mathrm{~d}, 1 \mathrm{H}), 7.8(\mathrm{~s}, 1 \mathrm{H}), 7.0(\mathrm{~s}, 1 \mathrm{H}), 6.6(\mathrm{~m}, 4 \mathrm{H}), 5.85(\mathrm{~s}, 2 \mathrm{H}), 4.0(\mathrm{~m}, 5 \mathrm{H}), 3.3$ (m, $2 \mathrm{H}), 3.2(\mathrm{q}, 2 \mathrm{H}), 2.9(\mathrm{~d}, 1 \mathrm{H}), 2.8(\mathrm{~d}, 1 \mathrm{H}), 2.6(\mathrm{~m}, 2 \mathrm{H}), 2.4(\mathrm{~d}, 1 \mathrm{H}), 2.25(\mathrm{~m}, 1 \mathrm{H})$, 1.15 (t, $3 \mathrm{H})$. Anal. $\left(\mathrm{C}_{25} \mathrm{H}_{29} \mathrm{~N}_{7} \mathrm{O}_{5} \cdot 0.4 \mathrm{H}_{2} \mathrm{O}\right) \mathrm{C}, \mathrm{H}, \mathrm{N}$.

N-[(1,3-benzodioxol-5-yl)methyl]-1-[2-(1H-imidazol-1-yl)pyrimidin-4-yl]-4-(1iminoethyl)-2-piperazineacetamide, hydrochloride (11v). NMR (DMSO-d $\left.\mathrm{d}_{6}\right) \delta 9.5(\mathrm{~m}$, $1 \mathrm{H}), 8.9(\mathrm{~s}, 1 \mathrm{H}), 8.6(\mathrm{~m}, 2 \mathrm{H}), 8.25(\mathrm{~m}, 1 \mathrm{H}), 7.9(\mathrm{~m}, 1 \mathrm{H}), 7.05(\mathrm{~s}, 1 \mathrm{H}), 6.7(\mathrm{~m}, 4 \mathrm{H})$, $5.9(\mathrm{~s}, 2 \mathrm{H}), 4.1(\mathrm{~m}, 2 \mathrm{H}), 4.0(\mathrm{~m}, 3 \mathrm{H}), 3.1-3.8(\mathrm{~m}, 4 \mathrm{H}), 2.6(\mathrm{~m}, 2 \mathrm{H}), 2.35$ and $2.25(2 \mathrm{~s}$, $3 \mathrm{H})$. MS $463(\mathrm{M}+1)$. Anal. $\left(\mathrm{C}_{23} \mathrm{H}_{26} \mathrm{~N}_{8} \mathrm{O}_{3} \cdot \mathrm{H}_{2} \mathrm{O}\right) \mathrm{C}, \mathrm{H}, \mathrm{N}$. 
$N-[(1,3-b e n z o d i o x o l-5-y l) m e t h y l]-4-[(5-d i m e t h y l a m i n o n a p h t h y l) s u l f o n y l]-1-$ [2-(1H-imidazol-1-yl)pyrimidin-4-yl]-2-piperazineacetamide (11w). NMR $\left(\mathrm{CDCl}_{3}\right)$ $\delta 8.6(\mathrm{~d}, 1 \mathrm{H}), 8.5(\mathrm{~s}, 1 \mathrm{H}), 8.3(\mathrm{~d}, 1 \mathrm{H}), 8.2(\mathrm{~d}, 1 \mathrm{H}), 8.1(\mathrm{~d}, 1 \mathrm{H}), 7.8(\mathrm{~s}, 1 \mathrm{H}), 7.6(\mathrm{~m}, 2$ H), $7.2(\mathrm{~d}, 1 \mathrm{H}), 7.1(\mathrm{~s}, 1 \mathrm{H}), 6.8(\mathrm{~m}, 3 \mathrm{H}), 6.6(\mathrm{br} \mathrm{s}, 1 \mathrm{H}), 6.0(\mathrm{~s}, 2 \mathrm{H}), 4.3(\mathrm{~m}, 1 \mathrm{H}), 4.2$ (m, $1 \mathrm{H}), 4.1(\mathrm{~d}, 1 \mathrm{H}), 3.7(\mathrm{~d}, 1 \mathrm{H}), 3.2(\mathrm{br} \mathrm{s}, 1 \mathrm{H}), 2.9(\mathrm{~s}, 6 \mathrm{H}), 2.8(\mathrm{~m}, 4 \mathrm{H}), 2.3(\mathrm{dd}, 1$ H). Anal. $\left(\mathrm{C}_{33} \mathrm{H}_{34} \mathrm{~N}_{8} \mathrm{O}_{5} \mathrm{~S} . \mathrm{CH}_{2} \mathrm{Cl}_{2}\right) \mathrm{C}, \mathrm{H}, \mathrm{N}$.

N-[(1,3-benzodioxol-5-yl)methyl]-1-[2-(1H-imidazol-1-yl)-4-pyrimidinyl]-2piperidineacetamide (12a). NMR $\left(\mathrm{CDCl}_{3}\right) \delta 8.45(\mathrm{~s}, 1 \mathrm{H}), 8.1(\mathrm{~d}, 1 \mathrm{H}), 7.85(\mathrm{~s}, 1 \mathrm{H})$, $7.05(\mathrm{~s}, 1 \mathrm{H}), 6.7(\mathrm{~s}, 1 \mathrm{H}), 6.5(\mathrm{~m}, 4 \mathrm{H}), 5.85(\mathrm{~m}, 2 \mathrm{H}), 5.1(\mathrm{br}, 1 \mathrm{H}), 4.2(\mathrm{~m}, 3 \mathrm{H}), 3.0(\mathrm{~m}$, $1 \mathrm{H}), 2.7$ (dd, $1 \mathrm{H}), 2.55$ (dd, $1 \mathrm{H}), 1.6-1.8(\mathrm{~m}, 5 \mathrm{H}), 1.5(\mathrm{~m}, 1 \mathrm{H})$. Anal. $\left(\mathrm{C}_{22} \mathrm{H}_{24} \mathrm{~N}_{6} \mathrm{O}_{3} \cdot 0.7\right.$ $\left.\mathrm{CH}_{2} \mathrm{Cl}_{2}\right) \mathrm{C}, \mathrm{H}, \mathrm{N}$.

1-[2-(1H-imidazol-1-yl)-4-pyrimidinyl]-N-[(4-methoxyphenyl)methyl]-2piperidineacetamide (12b). NMR $\left(\mathrm{CDCl}_{3}\right) \delta 8.45(\mathrm{~s}, 1 \mathrm{H}), 8.1(\mathrm{~d}, 1 \mathrm{H}), 7.75(\mathrm{~s}, 1 \mathrm{H}), 7.1$ (s, $1 \mathrm{H}), 7.0(\mathrm{~d}, 2 \mathrm{H}), 6.7(\mathrm{~d}, 2 \mathrm{H}), 6.5(\mathrm{~s}, 1 \mathrm{H}), 6.25(\mathrm{~m}, 1 \mathrm{H}), 5.1(\mathrm{br}, 1 \mathrm{H}), 4.25(\mathrm{~m}, 3 \mathrm{H})$, $3.75(\mathrm{~s}, 3 \mathrm{H}), 2.59(\mathrm{~m}, 1 \mathrm{H}), 2.65(\mathrm{dd}, 1 \mathrm{H}), 2.55(\mathrm{dd}, 1 \mathrm{H}), 1.3-1.8(\mathrm{~m}, 6 \mathrm{H})$. Anal. $\left(\mathrm{C}_{22} \mathrm{H}_{26} \mathrm{~N}_{6} \mathrm{O}_{2} \cdot 0.8 \mathrm{H}_{2} \mathrm{O}\right) \mathrm{C}, \mathrm{H}, \mathrm{N}$.

1-[2-(1H-imidazol-1-yl)pyrimidin-4-yl]-N-[(3-methoxyphenyl)methyl]-2-

piperidineacetamide (12c). NMR $\left(\mathrm{CDCl}_{3}\right) \delta 8.4(\mathrm{~s}, 1 \mathrm{H}), 8.0(\mathrm{~m}, 1 \mathrm{H}), 7.75(\mathrm{~s}, 1 \mathrm{H}), 7.3$ (m, $1 \mathrm{H}), 7.05(\mathrm{t}, 1 \mathrm{H}), 6.95(\mathrm{~s}, 1 \mathrm{H}), 6.6(\mathrm{~m}, 3 \mathrm{H}), 6.6(\mathrm{~m}, 1 \mathrm{H}), 5.0(\mathrm{br}, 1 \mathrm{H}), 4.25(\mathrm{~m}, 3$ H), $3.65(\mathrm{~s}, 3 \mathrm{H}), 2.9(\mathrm{~m}, 3 \mathrm{H}), 2.6(\mathrm{~m}, 2 \mathrm{H}), 1.3-1.8(\mathrm{~m}, 6 \mathrm{H})$. Anal. $\left(\mathrm{C}_{22} \mathrm{H}_{26} \mathrm{~N}_{6} \mathrm{O}_{2} \cdot 0.3\right.$ $\left.\mathrm{H}_{2} \mathrm{O}\right) \mathrm{C}, \mathrm{H}, \mathrm{N}$.

1-[2-(1H-imidazol-1-yl)pyrimidin-4-yl]-N-[(2-methoxyphenyl)methyl]-2piperidineacetamide (12d). NMR $\left(\mathrm{CDCl}_{3}\right) \delta 8.4(\mathrm{~s}, 1 \mathrm{H}), 8.0(\mathrm{~d}, 1 \mathrm{H}), 7.8(\mathrm{~s}, 1 \mathrm{H}), 7.1$ 
$(\mathrm{m}, 2 \mathrm{H}), 6.7(\mathrm{~m}, 2 \mathrm{H}), 6.4(\mathrm{~d}, 1 \mathrm{H}), 6.3(\mathrm{~m}, 1 \mathrm{H}), 5.0(\mathrm{br} \mathrm{s}, 1 \mathrm{H}), 4.3(\mathrm{~m}, 2 \mathrm{H}), 3.8(\mathrm{~s}, 3$

H), $2.9(\mathrm{~m}, 1 \mathrm{H}), 2.8(\mathrm{~m}, 2 \mathrm{H}), 2.0(\mathrm{~m}, 1 \mathrm{H}), 1.7(\mathrm{~m}, 5 \mathrm{H}), 1.5(\mathrm{~m}, 1 \mathrm{H})$. Anal.

$\left(\mathrm{C}_{22} \mathrm{H}_{26} \mathrm{~N}_{6} \mathrm{O}_{2} \cdot \mathrm{H}_{2} \mathrm{O}\right) \mathrm{C}, \mathrm{H}, \mathrm{N}$.

1-[2-(1H-imidazol-1-yl)pyrimidin-4-yl]-N-[(3,4-dimethoxyphenyl)methyl]-2-

piperidineacetamide (12e). NMR (DMSO- $\left.\mathrm{d}_{6}\right) \delta 8.5(\mathrm{~s}, 1 \mathrm{H}), 8.4(\mathrm{~m}, 1 \mathrm{H}), 8.15(\mathrm{~d}, 1 \mathrm{H})$, $7.85(\mathrm{~s}, 1 \mathrm{H}), 7.05(\mathrm{~s}, 1 \mathrm{H}), 6.7(\mathrm{~m}, 3 \mathrm{H}), 6.6(\mathrm{~d}, 1 \mathrm{H}), 4.1(\mathrm{~m}, 2 \mathrm{H}), 3.6(2 \mathrm{~s}, 6 \mathrm{H}), 3.1(\mathrm{~m}$, $1 \mathrm{H}), 3.0(\mathrm{~m}, 2 \mathrm{H})$, 1.3-1.8 (m, $6 \mathrm{H})$. Anal. $\left(\mathrm{C}_{23} \mathrm{H}_{28} \mathrm{~N}_{6} \mathrm{O}_{3} \cdot \mathrm{H}_{2} \mathrm{O}\right) \mathrm{C}, \mathrm{H}, \mathrm{N}$.

1-[2-(1H-imidazol-1-yl)pyrimidin-4-yl]-N-[(3, 4, 5-trimethoxyphenyl)methyl]-2piperidineacetamide (12f). NMR $\left(\mathrm{CDCl}_{3}\right) \delta 8.5(\mathrm{~s}, 1 \mathrm{H}), 8.1(\mathrm{~d}, 1 \mathrm{H}), 7.8(\mathrm{~s}, 1 \mathrm{H}), 7.1(\mathrm{~s}$, $1 \mathrm{H}), 6.5(\mathrm{~m}, 1 \mathrm{H}), 6.3(\mathrm{~s}, 2 \mathrm{H}), 6.2(\mathrm{br}, 1 \mathrm{H}), 5.15(\mathrm{br}, 1 \mathrm{H}), 4.4(\mathrm{dd}, 1 \mathrm{H}), 4.2(\mathrm{~m}, 1 \mathrm{H})$, $3.82(\mathrm{~s}, 3 \mathrm{H}), 3.77(\mathrm{~s}, 6 \mathrm{H}), 3.0(\mathrm{~m}, 1 \mathrm{H}), 2.7(\mathrm{dd}, 1 \mathrm{H}), 2.55(\mathrm{dd}, 1 \mathrm{H}), 1.3-1.8(\mathrm{~m}, 6 \mathrm{H})$. Anal. $\left(\mathrm{C}_{24} \mathrm{H}_{30} \mathrm{~N}_{6} \mathrm{O}_{4}\right) \mathrm{C}, \mathrm{H}, \mathrm{N}$.

1-[2-(1H-imidazol-1-yl)pyrimidin-4-yl]-N-(phenylmethyl)-2piperidineacetamide (12g). NMR $\left(\mathrm{CDCl}_{3}\right) \delta 8.4(\mathrm{~s}, 1 \mathrm{H}), 8.05(\mathrm{~d}, 1 \mathrm{H}), 7.75(\mathrm{~s}, 1 \mathrm{H})$, 7.0-7.3 (m, $6 \mathrm{H}), 6.7(\mathrm{br}, 1 \mathrm{H}), 6.5(\mathrm{~m}, 1 \mathrm{H}), 5.15(\mathrm{br}, 1 \mathrm{H}), 4.3(\mathrm{~m}, 1 \mathrm{H}), 2.95(\mathrm{~m}, 1 \mathrm{H})$, $2.65(\mathrm{dd}, 1 \mathrm{H}), 2.55(\mathrm{dd}, 1 \mathrm{H}), 1.3-1.8(\mathrm{~m}, 6 \mathrm{H})$. Anal. $\left(\mathrm{C}_{24} \mathrm{H}_{24} \mathrm{~N}_{6} \mathrm{O} .0 .2 \mathrm{H}_{2} \mathrm{O}\right) \mathrm{C}, \mathrm{H}, \mathrm{N}$.

N-[(4-chlorophenyl)methyl]-1-[2-(1H-imidazol-1-yl)pyrimidin-4-yl]-2-

piperidineacetamide (12h). NMR $\left(\mathrm{CDCl}_{3}\right) \delta 8.65(\mathrm{br}, 1 \mathrm{H}), 8.05(\mathrm{~d}, 1 \mathrm{H}), 7.8(\mathrm{~s}, 1 \mathrm{H})$, $7.4(\mathrm{br}, 1 \mathrm{H}), 7.0(\mathrm{~m}, 5 \mathrm{H}), 6.5(\mathrm{~m}, 1 \mathrm{H}), 5.2(\mathrm{br}, 1 \mathrm{H}), 4.2(\mathrm{~m}, 2 \mathrm{H}), 3.65(\mathrm{~m}, 1 \mathrm{H}), 3.05$ (m, $1 \mathrm{H}), 2.75(\mathrm{dd}, 1 \mathrm{H}), 2.6(\mathrm{dd}, 1 \mathrm{H}), 1.3-1.8(\mathrm{~m}, 6 \mathrm{H})$. Anal. $\left(\mathrm{C}_{21} \mathrm{H}_{23} \mathrm{~N}_{6} \mathrm{OCl} .0 .8 \mathrm{H}_{2} \mathrm{O}\right) \mathrm{C}$, $\mathrm{H}, \mathrm{N}$.

$N$-[(4-fluorophenyl)methyl]-1-[2-(1H-imidazol-1-yl)pyrimidin-4-yl]-2-

piperidineacetamide (12i). NMR $\left(\mathrm{CDCl}_{3}\right) \delta 8.4(\mathrm{~s}, 1 \mathrm{H}), 8.05(\mathrm{~d}, 1 \mathrm{H}), 7.75(\mathrm{~s}, 1 \mathrm{H}), 7.0$ 
$(\mathrm{m}, 3 \mathrm{H}), 6.8(\mathrm{~m}, 2 \mathrm{H}), 6.7(\mathrm{~m}, 1 \mathrm{H}), 6.5(\mathrm{~m}, 1 \mathrm{H}), 5.1(\mathrm{br}, 1 \mathrm{H}), 4.25(\mathrm{~m}, 3 \mathrm{H}), 3.0(\mathrm{~m}, 1$ $\mathrm{H}), 2.7(\mathrm{dd}, 1 \mathrm{H}), 2.55(\mathrm{dd}, 1 \mathrm{H}), 1.3-1.8(\mathrm{~m}, 6 \mathrm{H})$. Anal. $\left(\mathrm{C}_{21} \mathrm{H}_{23} \mathrm{~N}_{6} \mathrm{OF} .0 .8 \mathrm{H}_{2} \mathrm{O}\right) \mathrm{C}, \mathrm{H}, \mathrm{N}$. 1-[2-(1H-imidazol-1-yl)-4-pyrimidinyl]- $N$-[[4(trifluoromethoxy)phenyl]methyl]-2-piperidineacetamide (12j). NMR $\left(\mathrm{CDCl}_{3}\right) \delta 8.5$ (s, $1 \mathrm{H}), 8.1(\mathrm{~d}, 1 \mathrm{H}), 7.8(\mathrm{~s}, 1 \mathrm{H}), 7.1(\mathrm{~m}, 4 \mathrm{H}), 6.5(\mathrm{~d}, 1 \mathrm{H}), 6.4(\mathrm{br} \mathrm{s}, 1 \mathrm{H}), 5.2(\mathrm{br} \mathrm{s}, 1$ H), $4.3(\mathrm{~m}, 2 \mathrm{H}), 3.0(\mathrm{~m}, 1 \mathrm{H}), 2.6(\mathrm{~m}, 2 \mathrm{H}), 1.8(\mathrm{~m}, 6 \mathrm{H}$, partially obscured by water), 1.6 (m, $1 \mathrm{H})$. Anal. $\left(\mathrm{C}_{22} \mathrm{H}_{23} \mathrm{~F}_{3} \mathrm{~N}_{6} \mathrm{O}_{2} \mathrm{H}_{2} \mathrm{O}\right) \mathrm{C}, \mathrm{H}, \mathrm{N}$.

\section{1-[2-(1H-imidazol-1-yl)pyrimidin-4-yl]-N-[(4-methylphenyl)methyl]-2-} piperidineacetamide (12k). NMR $\left(\mathrm{CDCl}_{3}\right) \delta 8.4(\mathrm{~s}, 1 \mathrm{H}), 8.03(\mathrm{~d}, 1 \mathrm{H}), 7.75(\mathrm{~s}, 1 \mathrm{H})$, $6.95(\mathrm{~m}, 5 \mathrm{H}), 6.8(\mathrm{~s}, 1 \mathrm{H}), 6.45(\mathrm{~s}, 1 \mathrm{H}), 5.0(\mathrm{br}, 1 \mathrm{H}), 4.25(\mathrm{~m}, 3 \mathrm{H}), 2.9(\mathrm{~m}, 1 \mathrm{H}), 2.6$ (m, $1 \mathrm{H}), 2.5(\mathrm{~m}, 1 \mathrm{H}), 2.2(\mathrm{~s}, 3 \mathrm{H}), 1.3-1.8(\mathrm{~m}, 6 \mathrm{H})$. Anal. $\left(\mathrm{C}_{23} \mathrm{H}_{28} \mathrm{~N}_{6} \mathrm{O}_{3} \cdot \mathrm{H}_{2} \mathrm{O} .0 .6 \mathrm{H}_{2} \mathrm{O}\right) \mathrm{C}$, $\mathrm{H}, \mathrm{N}$.

\section{$N$-[(4-aminophenyl)methyl]-1-[2-(1H-imidazol-1-yl)-4-pyrimidinyl]-2-}

piperidineacetamide (12) $)$ NMR $\left(\mathrm{CDCl}_{3}\right) \delta 8.4(\mathrm{~s}, 1 \mathrm{H}), 8.1(\mathrm{~d}, 1 \mathrm{H}), 7.7(\mathrm{~s}, 1 \mathrm{H}), 7.0(\mathrm{~s}$, $1 \mathrm{H}), 6.8(\mathrm{~d}, 2 \mathrm{H}), 6.5(\mathrm{~m}, 3 \mathrm{H}), 6.0(\mathrm{br} \mathrm{s}, 1 \mathrm{H}), 5.1(\mathrm{~s}, 1 \mathrm{H}), 4.2(\mathrm{~m}, 2 \mathrm{H}), 2.9(\mathrm{~m}, 1 \mathrm{H})$, $2.6(\mathrm{~m}, 2 \mathrm{H}), 1.7(\mathrm{~m}, 6 \mathrm{H}), 1.5(\mathrm{~m}, 1 \mathrm{H})$. Anal. $\left(\mathrm{C}_{21} \mathrm{H}_{25} \mathrm{~N}_{7} \mathrm{O} . \mathrm{CH}_{2} \mathrm{Cl}_{2}\right) \mathrm{C}, \mathrm{H}, \mathrm{N}$.

\section{1-[2-(1H-imidazol-1-yl)-4-pyrimidinyl]-N-[[4-}

(methylsulfonylamino)phenyl]methyl]-2-piperidineacetamide (12m). NMR (DMSO-

$\left.\mathrm{d}_{6}\right) \delta 9.6(\mathrm{~s}, 1 \mathrm{H}), 8.5(\mathrm{~s}, 1 \mathrm{H}), 8.4(\mathrm{~m}, 1 \mathrm{H}), 8.1(\mathrm{~d}, 1 \mathrm{H}), 7.8(\mathrm{~s}, 1 \mathrm{H}), 7.1(\mathrm{~m}, 5 \mathrm{H}), 6.7$ (m, $1 \mathrm{H}), 4.2(\mathrm{~m}, 1 \mathrm{H}), 4.1(\mathrm{~m}, 1 \mathrm{H}), 3.0(\mathrm{br} \mathrm{s}, 1 \mathrm{H}), 2.9(\mathrm{~s}, 3 \mathrm{H}), 2.5(\mathrm{~m}, 4 \mathrm{H}$, partially obscured by DMSO), $1.7(\mathrm{~m}, 5 \mathrm{H}), 1.4(\mathrm{~m}, 1 \mathrm{H})$. Anal. $\left(\mathrm{C}_{22} \mathrm{H}_{27} \mathrm{~N}_{7} \mathrm{O}_{3} \mathrm{~S} . \mathrm{CH}_{2} \mathrm{Cl}_{2}\right) \mathrm{C}, \mathrm{H}, \mathrm{N}$.

$N$-[(4-dimethylaminophenyl)methyl]-1-[2-(1H-imidazol-1-yl)pyrimidin-4-yl]-2piperidineacetamide (12n). NMR $\left(\mathrm{CDCl}_{3}\right) \delta 8.5(\mathrm{~s}, 1 \mathrm{H}), 8.1(\mathrm{~d}, 1 \mathrm{H}), 7.8(\mathrm{~s}, 1 \mathrm{H}), 7.1$ 
(s, $1 \mathrm{H}), 7.0(\mathrm{~d}, 2 \mathrm{H}), 6.5(\mathrm{~d}, 2 \mathrm{H}), 6.1(\mathrm{~s}, 1 \mathrm{H}), 5.1(\mathrm{br} \mathrm{s}, 1 \mathrm{H}), 4.2(\mathrm{~m}, 2 \mathrm{H}), 2.9(\mathrm{~m}, 1 \mathrm{H})$, $2.8(\mathrm{~s}, 6 \mathrm{H}), 2.6(\mathrm{~m}, 1 \mathrm{H}), 2.5(\mathrm{~m}, 1 \mathrm{H}), 2.0(\mathrm{~s}, 1 \mathrm{H}), 1.8(\mathrm{~m}, 5 \mathrm{H}), 1.5(\mathrm{~m}, 1 \mathrm{H})$. Anal.

$\left(\mathrm{C}_{23} \mathrm{H}_{29} \mathrm{~N}_{7} \mathrm{O} . \mathrm{CH}_{2} \mathrm{Cl}_{2}\right) \mathrm{C}, \mathrm{H}, \mathrm{N}$.

1-[2-(1H-imidazol-1-yl)-4-pyrimidinyl]- $N$-[[4-(trifluoromethyl)phenyl]methyl]2-piperidineacetamide (120). NMR $\left(\mathrm{CDCl}_{3}\right) \delta 8.4(\mathrm{~s}, 1 \mathrm{H}), 8.1(\mathrm{~d}, 1 \mathrm{H}), 7.8(\mathrm{~s}, 1 \mathrm{H}), 7.5$ (br s , $1 \mathrm{H}), 7.4$ (d, $2 \mathrm{H}), 7.2$ (d, $2 \mathrm{H}), 7.0(\mathrm{~s}, 1 \mathrm{H}), 6.5$ (s, $1 \mathrm{H}), 5.1$ (br s, $1 \mathrm{H}), 4.4(\mathrm{~m}, 2$ H), $3.0(\mathrm{~m}, 1 \mathrm{H}), 2.6(\mathrm{~m}, 2 \mathrm{H}), 2.5(\mathrm{br} \mathrm{s}, 1 \mathrm{H}), 1.7(\mathrm{~m}, 5 \mathrm{H}), 1.5(\mathrm{~m}, 1 \mathrm{H})$. Anal. $\left(\mathrm{C}_{22} \mathrm{H}_{23} \mathrm{~F}_{3} \mathrm{~N}_{6} \mathrm{O} . \mathrm{CH}_{2} \mathrm{Cl}_{2}\right) \mathrm{C}, \mathrm{H}, \mathrm{N}$.

N-[(4-cyanophenyl)methyl]-1-[2-(1H-imidazol-1-yl)pyrimidin-4-yl]-2piperidineacetamide (12p). NMR $\left(\mathrm{CDCl}_{3}\right) \delta 8.4(\mathrm{~s}, 1 \mathrm{H}), 8.1(\mathrm{~d}, 1 \mathrm{H}), 7.8(\mathrm{~s}, 1 \mathrm{H}), 7.4$ (d, $2 \mathrm{H}), 7.2(\mathrm{~d}, 2 \mathrm{H}), 7.0(\mathrm{~s}, 1 \mathrm{H}), 6.8(\mathrm{~m}, 1 \mathrm{H}), 6.5(\mathrm{~m}, 1 \mathrm{H}), 5.2(\mathrm{br} \mathrm{s}, 1 \mathrm{H}), 4.4(\mathrm{~m}, 2 \mathrm{H})$, $3.0(\mathrm{~m}, 1 \mathrm{H}), 2.8(\mathrm{dd}, 1 \mathrm{H}), 2.6(\mathrm{dd}, 1 \mathrm{H}), 1.8(\mathrm{~m}, 5 \mathrm{H}), 1.6(\mathrm{~m}, 1 \mathrm{H})$. Anal. $\left(\mathrm{C}_{22} \mathrm{H}_{23} \mathrm{~N}_{7} \mathrm{O} . \mathrm{CH}_{2} \mathrm{Cl}_{2}\right) \mathrm{C}, \mathrm{H}, \mathrm{N}$.

1-[2-(1H-imidazol-1-yl)pyrimidin-4-yl]-N-[(4-nitrophenyl)methyl]-2piperidineacetamide (12q). NMR $\left(\mathrm{CDCl}_{3}\right) \delta 8.4(\mathrm{~s}, 1 \mathrm{H}), 8.1(\mathrm{~d}, 1 \mathrm{H}), 8.0(\mathrm{~d}, 2 \mathrm{H}), 7.8$ (s, $1 \mathrm{H}), 7.2(\mathrm{~d}, 2 \mathrm{H}), 7.1(\mathrm{~s}, 1 \mathrm{H}), 6.5(\mathrm{~d}, 1 \mathrm{H}), 5.2(\mathrm{br} \mathrm{s}, 1 \mathrm{H}), 4.5(\mathrm{dd}, 1 \mathrm{H}), 4.3(\mathrm{dd}, 1 \mathrm{H})$, $3.1(\mathrm{~m}, 1 \mathrm{H}), 2.8(\mathrm{dd}, 1 \mathrm{H}), 2.6(\mathrm{dd}, 1 \mathrm{H}), 1.8(\mathrm{~m}, 4 \mathrm{H}), 1.6(\mathrm{~m}, 3 \mathrm{H}$, partially obscured by water). Anal. $\left(\mathrm{C}_{21} \mathrm{H}_{23} \mathrm{~N}_{7} \mathrm{O}_{3} . \mathrm{CH}_{2} \mathrm{Cl}_{2}\right) \mathrm{C}, \mathrm{H}, \mathrm{N}$.

N-[(4-aminosulfonylphenyl)methyl]-1-[2-(1H-imidazol-1-yl)pyrimidin-4-yl]-2piperidineacetamide (12r). NMR (DMSO-d 6 ) $\delta 8.6(\mathrm{~s}, 2 \mathrm{H}), 8.2(\mathrm{~d}, 1 \mathrm{H}), 7.8(\mathrm{~s}, 1 \mathrm{H})$, $7.7(\mathrm{~d}, 2 \mathrm{H}), 7.3(\mathrm{~m}, 4 \mathrm{H}), 7.1(\mathrm{~s}, 1 \mathrm{H}), 6.7(\mathrm{~d}, 1 \mathrm{H}), 4.2(\mathrm{~m}, 2 \mathrm{H}), 3.0(\mathrm{~m}, 1 \mathrm{H}), 2.5(\mathrm{~m}, 3$ $\mathrm{H}$, partially obscured by DMSO), $2.3(\mathrm{~m}, 1 \mathrm{H}), 1.6(\mathrm{~m}, 5 \mathrm{H}), 1.4(\mathrm{~m}, 1 \mathrm{H})$. Anal. $\left(\mathrm{C}_{21} \mathrm{H}_{25} \mathrm{~N}_{7} \mathrm{O}_{3}\right) \mathrm{C}, \mathrm{H}, \mathrm{N}$. 
1-[2-(1H-imidazol-1-yl)-4-pyrimidinyl]-N-[[4-(methylsulfonyl)phenyl]methyl]2-piperidineacetamide (12s). $\operatorname{NMR}\left(\mathrm{CDCl}_{3}\right) \delta 8.4(\mathrm{~s}, 1 \mathrm{H}), 8.1(\mathrm{~d}, 1 \mathrm{H}), 7.8(\mathrm{~s}, 1 \mathrm{H}), 7.6$ (d, $2 \mathrm{H}), 7.4(\mathrm{~s}, 1 \mathrm{H}), 7.2$ (d, $2 \mathrm{H}), 7.0(\mathrm{~s}, 1 \mathrm{H}), 6.5(\mathrm{~s}, 1 \mathrm{H}), 5.1$ (br s, $1 \mathrm{H}), 4.4(\mathrm{~m}, 2 \mathrm{H})$, $3.0(\mathrm{~s}, 4 \mathrm{H}), 2.7(\mathrm{~m}, 2 \mathrm{H}), 2.4(\mathrm{~s}, 1 \mathrm{H}), 1.8(\mathrm{~m}, 5 \mathrm{H}), 1.5(\mathrm{~m}, 1 \mathrm{H})$. Anal.

$\left(\mathrm{C}_{22} \mathrm{H}_{26} \mathrm{~N}_{6} \mathrm{O}_{3} \mathrm{~S} . \mathrm{CH}_{2} \mathrm{Cl}_{2}\right) \mathrm{C}, \mathrm{H}, \mathrm{N}$.

1-[2-(1H-imidazol-1-yl)-4-pyrimidinyl]-N-[(2-furanyl)methyl]-2-

piperidineacetamide (12t). NMR $\left(\mathrm{CDCl}_{3}\right) \delta 8.45(\mathrm{~s}, 1 \mathrm{H}), 8.05(\mathrm{~d}, 1 \mathrm{H}), 7.8(\mathrm{~s}, 1 \mathrm{H}), 7.2$ (s, $1 \mathrm{H}), 7.05(\mathrm{~s}, 1 \mathrm{H}), 6.7(\mathrm{~m}, 1 \mathrm{H}), 6.5(\mathrm{~m}, 1 \mathrm{H}), 6.2(\mathrm{~s}, 1 \mathrm{H}), 6.05(\mathrm{~s}, 1 \mathrm{H}), 5.1(\mathrm{br} \mathrm{s}, 1 \mathrm{H})$, $4.3(\mathrm{~m}, 3 \mathrm{H}), 2.95(\mathrm{~m}, 1 \mathrm{H}), 2.6(\mathrm{~m}, 2 \mathrm{H}), 1.7(\mathrm{~m}, 5 \mathrm{H}), 1.5(\mathrm{~m}, 1 \mathrm{H})$. Anal. $\left(\mathrm{C}_{19} \mathrm{H}_{22} \mathrm{~N}_{6} \mathrm{O}_{2}\right.$. $\left.0.5 \mathrm{H}_{2} \mathrm{O}\right) \mathrm{C}, \mathrm{H}, \mathrm{N}$.

1-[2-(1H-imidazol-1-yl)-4-pyrimidinyl]-N-[(2-pyridinyl)methyl]-2piperidineacetamide (12u). NMR $\left(\mathrm{CDCl}_{3}\right) \delta 8.45(\mathrm{~s}, 1 \mathrm{H}), 8.4(\mathrm{~m}, 1 \mathrm{H}), 8.05(\mathrm{~d}, 1 \mathrm{H})$, $7.8(\mathrm{~s}, 1 \mathrm{H}), 7.55(\mathrm{t}, 1 \mathrm{H}), 7.0-7.2(\mathrm{~m}, 4 \mathrm{H}), 6.5(\mathrm{~m}, 1 \mathrm{H}), 5.1$ (br s, $1 \mathrm{H}), 4.4(\mathrm{~m}, 2 \mathrm{H}), 4.4$ (br, 1H), $3.0(\mathrm{~m}, 1 \mathrm{H}), 2.6(\mathrm{~m}, 2 \mathrm{H}), 1.7(\mathrm{~m}, 5 \mathrm{H}), 1.5(\mathrm{~m}, 1 \mathrm{H})$. Anal. $\left(\mathrm{C}_{20} \mathrm{H}_{23} \mathrm{~N}_{7} \mathrm{O} .0 .4\right.$ $\left.\mathrm{H}_{2} \mathrm{O}\right) \mathrm{C}, \mathrm{H}, \mathrm{N}$.

1-[2-(1H-imidazol-1-yl)-4-pyrimidinyl]-N-methyl-N-phenyl-2-

piperidineacetamide (12v). NMR (DMSO-d) $\delta 8.45(\mathrm{~m}, 1 \mathrm{H}), 8.1(\mathrm{~m}, 1 \mathrm{H}), 7.8(\mathrm{~m}, 1 \mathrm{H})$, $7.2(\mathrm{~m}, 3 \mathrm{H}), 7.05(\mathrm{~m}, 3 \mathrm{H}), 6.7(\mathrm{dd}, 1 \mathrm{H}), 4.6(\mathrm{~m}, 1 \mathrm{H}), 4.45(\mathrm{~m}, 2 \mathrm{H}), 2.85(\mathrm{~m}, 3 \mathrm{H}), 2.9$ and $2.75(2 \mathrm{~s}, 3 \mathrm{H}), 1.4-1.8(\mathrm{~m}, 6 \mathrm{H})$. Anal. $\left(\mathrm{C}_{20} \mathrm{H}_{23} \mathrm{~N}_{7} \mathrm{O} .0 .4 \mathrm{H}_{2} \mathrm{O}\right) \mathrm{C}, \mathrm{H}, \mathrm{N}$.

1-[2-(1H-imidazol-1-yl)-4-pyrimidinyl]-N-[(diphenyl)methyl]-2piperidineacetamide (12w). NMR $\left(\mathrm{CDCl}_{3}\right) \delta 8.45(\mathrm{~s}, 1 \mathrm{H}), 8.05(\mathrm{~d}, 1 \mathrm{H}), 7.75(\mathrm{~s}, 1 \mathrm{H})$, 6.9-7.4 (m, $12 \mathrm{H}), 6.45(\mathrm{~m}, 1 \mathrm{H}), 6.2(\mathrm{~d}, 1 \mathrm{H}), 5.1(\mathrm{br} \mathrm{s}, 1 \mathrm{H}), 4.4(\mathrm{br}, 1 \mathrm{H}), 3.0(\mathrm{~m}, 1 \mathrm{H})$, 
$2.8(\mathrm{dd}, 1 \mathrm{H}), 2.55(\mathrm{dd}, 1 \mathrm{H}), 1.7(\mathrm{~m}, 5 \mathrm{H}), 1.5(\mathrm{~m}, 1 \mathrm{H})$. Anal. $\left(\mathrm{C}_{27} \mathrm{H}_{28} \mathrm{~N}_{6} \mathrm{O} .0 .5 \mathrm{H}_{2} \mathrm{O}\right) \mathrm{C}$, $\mathrm{H}, \mathrm{N}$.

1-[2-(1H-imidazol-1-yl)pyrimidin-4-yl]-N-methyl-2-piperidineacetamide (12x). NMR (DMSO-d $\left.)_{6}\right) \delta 8.45(\mathrm{~s}, 1 \mathrm{H}), 8.15(\mathrm{~d}, 1 \mathrm{H}), 7.85(\mathrm{~s}, 1 \mathrm{H}), 7.55(\mathrm{br}, 1 \mathrm{H}), 7.05(\mathrm{~s}, 1 \mathrm{H})$, $6.65(\mathrm{~d}, 1 \mathrm{H}), 5.0(\mathrm{br}, 1 \mathrm{H}), 4.25(\mathrm{~m}, 1 \mathrm{H}), 2.4(\mathrm{~m}, 2 \mathrm{H}), 1.3-1.8(\mathrm{~m}, 6 \mathrm{H})$. Anal. $\left(\mathrm{C}_{15} \mathrm{H}_{20} \mathrm{~N}_{6} \mathrm{O} .0 .1 \mathrm{CH}_{2} \mathrm{Cl}_{2} \cdot 0.9 \mathrm{H}_{2} \mathrm{O}\right) \mathrm{C}, \mathrm{H}, \mathrm{N}$.

N-[(2-benzimidazolyl)methyl]-1-[2-(1H-imidazol-1-yl)pyrimidin-4-yl]-2piperidineacetamide (12y). NMR (DMSO- $\left.\mathrm{d}_{6}\right) \delta 8.7(\mathrm{~m}, 1 \mathrm{H}), 8.5(\mathrm{~s}, 1 \mathrm{H}), 8.15(\mathrm{~d}, 1 \mathrm{H})$, 7.85 (s, 1 H), 7.45 (m, 2 H), 7.15 (m, 2 H), 7.05 (s, 1 H), 6.7 (d, 2 H), 5.3 (br, 2 H), 4.6 (br $1 \mathrm{H}), 4.4(\mathrm{~m}, 2 \mathrm{H}), 3.0(\mathrm{~m}, 1 \mathrm{H}), 2.6(\mathrm{~m}, 1 \mathrm{H}), 2.5(\mathrm{~m}, 1 \mathrm{H}), 1.7(\mathrm{~m}, 5 \mathrm{H}), 1.4(\mathrm{~m}, 1 \mathrm{H})$. Anal. $\left(\mathrm{C}_{22} \mathrm{H}_{24} \mathrm{~N}_{8} \mathrm{O}\right) \mathrm{C}, \mathrm{H}, \mathrm{N}$.

\section{$N-(1,3-b e n z o d i o x o l-5-y l)-1-[2-(1 H$-imidazol-1-yl)pyrimidin-4-yl]-2-}

piperidineacetamide (12z). NMR (DMSO-d $\left.\mathrm{d}_{6}\right) \delta 9.9(\mathrm{~s}, 1 \mathrm{H}), 8.5(\mathrm{~s}, 1 \mathrm{H}), 8.15(\mathrm{~d}, 1 \mathrm{H})$, 7.85 (s, 1 H), $7.15(\mathrm{~s}, 1 \mathrm{H}), 7.05$ (m, $1 \mathrm{H}), 6.75(\mathrm{~m}, 3 \mathrm{H}), 5.9(\mathrm{~s}, 2 \mathrm{H}), 3.1(\mathrm{~m}, 1 \mathrm{H}), 2.65$ (m, $2 \mathrm{H}), 1.7(\mathrm{~m}, 5 \mathrm{H}), 1.4(\mathrm{~m}, 1 \mathrm{H})$. Anal. $\left(\mathrm{C}_{21} \mathrm{H}_{28} \mathrm{~N}_{6} \mathrm{O}_{3} \cdot \mathrm{H}_{2} \mathrm{O}\right) \mathrm{C}, \mathrm{H}, \mathrm{N}$.

\section{N-(3,4-Dimethoxyphenyl)-1-[2-(1H-imidazol-1-yl)pyrimidin-4-yl]-2-}

piperidineacetamide (12aa). NMR (DMSO- $\left.\mathrm{d}_{6}, 100{ }^{\circ} \mathrm{C}\right) \delta 9.3(\mathrm{~s}, 1 \mathrm{H}), 8.5(\mathrm{~s}, 1 \mathrm{H}), 8.15$ (d, $1 \mathrm{H}), 7.85(\mathrm{~s}, 1 \mathrm{H}), 7.1$ (s, $1 \mathrm{H}), 7.0(\mathrm{~m}, 2 \mathrm{H}), 6.85(\mathrm{~d}, 1 \mathrm{H}), 6.7(\mathrm{~d}, 1 \mathrm{H}), 5.2(\mathrm{~s}, 1 \mathrm{H})$, $4.3(\mathrm{~d}, 1 \mathrm{H}), 3.8(\mathrm{~s}, 3 \mathrm{H}), 3.75(\mathrm{~s}, 3 \mathrm{H}), 3.1(\mathrm{~m}, 1 \mathrm{H}), 2.7(\mathrm{~m}, 2 \mathrm{H}), 1.3-1.8(\mathrm{~m}, 6 \mathrm{H})$. Anal. $\left(\mathrm{C}_{22} \mathrm{H}_{26} \mathrm{~N}_{6} \mathrm{O}_{3} .0 .2 \mathrm{CH}_{2} \mathrm{Cl}_{2}\right) \mathrm{C}, \mathrm{H}, \mathrm{N}$.

1-[2-(1H-imidazol-1-yl)-4-pyrimidinyl]-N-[2-(3,4-dimethoxyphenyl)ethyl]-2-

piperidineacetamide (12bb). NMR $\left(\mathrm{CDCl}_{3}\right) \delta 8.5(\mathrm{~s}, 1 \mathrm{H}), 8.1(\mathrm{~d}, 1 \mathrm{H}), 7.8(\mathrm{~s}, 1 \mathrm{H}), 7.1$ (s, $1 \mathrm{H}), 6.8(\mathrm{~s}, 1 \mathrm{H}), 6.6(\mathrm{~m}, 2 \mathrm{H}), 6.5(\mathrm{~m}, 1 \mathrm{H}), 5.95(\mathrm{br}, 1 \mathrm{H}), 5.0(\mathrm{br}, 1 \mathrm{H}), 3.8(2 \mathrm{~s}, 6$ 
H), $3.4(m, 2 H), 2.9(m, 1 H), 2.65(m, 2 H), 2.45(m, 2 H), 1.7(m, 6 H)$. Anal.

$\left(\mathrm{C}_{24} \mathrm{H}_{30} \mathrm{~N}_{6} \mathrm{O}_{3} \cdot 0.3 \mathrm{H}_{2} \mathrm{O} .0 .15 \mathrm{C}_{4} \mathrm{H}_{10} \mathrm{O}\right) \mathrm{C}, \mathrm{H}, \mathrm{N}$.

1-[2-(1H-imidazol-1-yl)-4-pyrimidinyl]-N-[2-(4-methoxyphenyl)ethyl]-2-

piperidineacetamide (12cc). NMR $\left(\mathrm{CDCl}_{3}\right) \delta 8.5(\mathrm{~s}, 1 \mathrm{H}), 8.1(\mathrm{~d}, 1 \mathrm{H}), 7.8(\mathrm{~s}, 1 \mathrm{H}), 7.1$

(s, $1 \mathrm{H}), 7.0(\mathrm{~d}, 2 \mathrm{H}), 6.8(\mathrm{~d}, 2 \mathrm{H}), 6.5(\mathrm{br} \mathrm{s}, 1 \mathrm{H}), 6.3(\mathrm{~m}, 1 \mathrm{H}), 5.0(\mathrm{br} \mathrm{s}, 1 \mathrm{H}), 3.8(\mathrm{~s}, 3$

H), $3.4(\mathrm{~m}, 2 \mathrm{H}), 2.9(\mathrm{~m}, 1 \mathrm{H}), 2.7(\mathrm{~m}, 2 \mathrm{H}), 2.4(\mathrm{~m}, 3 \mathrm{H}), 1.7(\mathrm{~m}, 6 \mathrm{H})$. Anal.

$\left(\mathrm{C}_{23} \mathrm{H}_{28} \mathrm{~N}_{6} \mathrm{O}_{2} \cdot \mathrm{CH}_{2} \mathrm{Cl}_{2}\right) \mathrm{C}, \mathrm{H}, \mathrm{N}$.

$N$-[(1,3-benzodioxol-5-yl)methyl]-4-[2-(1H-imidazol-1-yl)-4-pyrimidinyl]-3-

morpholineacetamide (13). $\cdot \mathrm{NMR}\left(\mathrm{CDCl}_{3}, 300 \mathrm{MHz}\right) \delta 2.45-2.55(\mathrm{dd}, 1 \mathrm{H}), 2.75-2.90$

(dd, $1 \mathrm{H}$ ), 3.20 (bt, $1 \mathrm{H}), 3.55-3.80(\mathrm{~m}, 2 \mathrm{H}), 3.85-4.20(\mathrm{~m}, 4 \mathrm{H}), 4.20-4.40(\mathrm{dd}, 2 \mathrm{H}), 5.90$

(d, 2H), $6.10(\mathrm{bs}, 1 \mathrm{H}), 6.25-6.75(\mathrm{~m}, 4 \mathrm{H}), 7.10(\mathrm{~m}, 1 \mathrm{H}), 7.80(\mathrm{~m}, 1 \mathrm{H}), 8.20(\mathrm{~d}, 1 \mathrm{H}), 8.50$ and 8.75 combined $(\mathrm{d}, 1 \mathrm{H}) ;(\mathrm{M}+\mathrm{H})^{+}: 423.5$.

$N$-[(1,3-benzodioxol-5-yl)methyl]hexahydro-1-[2-(1H-imidazol-1-yl)-4-

pyrimidinyl]-1H-azepine-2-acetamide (14). Prepared as described above from 1-

(dimethylethoxycarbonyl)hexahydro- $1 \mathrm{H}$-azepine-2-acetic acid. ${ }^{19} \mathrm{NMR}\left(\mathrm{CDCl}_{3}, 300\right.$

$M H z) \delta 1.10-3.00(m, 11 H), 3.20-3.62(m, 1 H), 4.05-4.50(m, 3 H), 5.00-5.30(m, 1 H)$,

5.80-6.10 (m, 2H), 6.25-6.90 (m, 4H), $7.05(\mathrm{~d}, 1 \mathrm{H}), 7.80(\mathrm{~d}, 1 \mathrm{H}), 8.10(\mathrm{~d}, 1 \mathrm{H}), 8.50(\mathrm{~d}$, $1 \mathrm{H}) ;(\mathrm{M}+\mathrm{H})^{+}: 435.3$.

N-[(1,3-benzodioxol-5-yl)methyl]-1-[4-(1H-imidazol-1-yl)-2-pyrimidinyl]-2-

piperidineacetamide (15). NMR $\left(\mathrm{CDCl}_{3}\right) \delta 8.3(\mathrm{~s}, 1 \mathrm{H}), 8.15(\mathrm{~m}, 1 \mathrm{H}), 7.6(\mathrm{~s}, 1 \mathrm{H}), 7.15$

(s, $1 \mathrm{H}), 6.95(\mathrm{br}, 1 \mathrm{H}), 6.6(\mathrm{~m}, 3 \mathrm{H}), 6.4(\mathrm{~d}, 1 \mathrm{H}), 5.9(\mathrm{~m}, 2 \mathrm{H}), 5.25(\mathrm{~m}, 1 \mathrm{H}), 4.7(\mathrm{~d}, 1$

H), 4.3 dd, 1 H), 4.15 (dd, 1 H), 3.0 (t, 1 H), 2.85 (dd, 1 H), 2.55 (dd, 1 H), 1.6-1.8 (m, 5

$\mathrm{H}), 1.5(\mathrm{~m}, 1 \mathrm{H})$. Anal. $\left(\mathrm{C}_{22} \mathrm{H}_{24} \mathrm{~N}_{6} \mathrm{O}_{3}\right) \mathrm{C}, \mathrm{H}, \mathrm{N}$. 


\section{N-[(1,3-benzodioxol-5-yl)methyl]-1-[4-(1H-imidazol-1-yl)-6-pyrimidinyl]-2-}

piperidineacetamide (16). NMR (DMSO- $\left.\mathrm{d}_{6}\right) \delta 8.5(\mathrm{~s}, 1 \mathrm{H}), 8.4(\mathrm{~m}, 2 \mathrm{H}), 7.95(\mathrm{~s}, 1 \mathrm{H})$, $7.1(\mathrm{~s}, 1 \mathrm{H}), 7.0(\mathrm{~s}, 1 \mathrm{H}), 6.7(\mathrm{~m}, 2 \mathrm{H}), 6.6(\mathrm{~d}, 1 \mathrm{H}), 5.9(\mathrm{~s}, 2 \mathrm{H}), 5.1(\mathrm{br}, 1 \mathrm{H}), 4.4(\mathrm{br}, 1$ H), $4.05(\mathrm{~m}, 2 \mathrm{H}), 3.03(\mathrm{t}, 1 \mathrm{H}), 2.5(\mathrm{~m}, 2 \mathrm{H}), 1.5-1.8(\mathrm{~m}, 5 \mathrm{H}), 1.3(\mathrm{~m}, 1 \mathrm{H})$. Anal. $\left(\mathrm{C}_{22} \mathrm{H}_{24} \mathrm{~N}_{6} \mathrm{O}_{3} \cdot 0.5 \mathrm{H}_{2} \mathrm{O}\right) \mathrm{C}, \mathrm{H}, \mathrm{N}$.

\section{N-(1,3-benzodioxol-5-ylmethyl)-1-[3-(1H-imidazol-1-yl)phenyl]-2-}

piperidineacetamide (17). A mixture of 1-(3-aminophenyl)imidazole ${ }^{20}$ (755 mg, 4.7 mmol), ethyl 7-chloro-3-oxoheptanoate ${ }^{21}$ (982 mg, 4.7 mmol), Na $2 \mathrm{HPO}$ (667 mg, 4.7 $\mathrm{mmol}$ ), iodine ( $60 \mathrm{mg}, 0.23 \mathrm{mmol}$ ) and $500 \mathrm{mg}$ of powdered $4 \mathrm{~A}$ molecular sieves in 20 $\mathrm{ml}$ of dry benzene is refluxed for $5 \mathrm{~h}$. Additional $60 \mathrm{mg}$ of iodine is added and the reaction mixture is refluxed overnight. After filtering the reaction mixture, the filtrate is evaporated and the residue is purified by chromatography (silica gel, methylene chloride:methanol 98:2) to yield $120 \mathrm{mg}(8 \%)$ of [1-[3-(1H-imidazol-1-yl)phenyl]-2piperedinylidine]ethanoic acid, ethyl ester. $\mathrm{NMR}\left(\mathrm{CDCl}_{3}\right): 7.85(\mathrm{~s}, 1 \mathrm{H})$, 7.05-7.50 (m, $6 \mathrm{H}), 4.80(\mathrm{~s}, 1 \mathrm{H}), 4.15(\mathrm{q}, 2 \mathrm{H}), 3.45(\mathrm{t}, 2 \mathrm{H}), 2.4(\mathrm{t}, 2 \mathrm{H}), 1.50-1.80(\mathrm{~m}, 6 \mathrm{H}), 1.30(\mathrm{t}, 3 \mathrm{H})$. The ester $(120 \mathrm{mg}, 0.38 \mathrm{mmol})$ is dissolved in methanol $(20 \mathrm{ml})$ and $10 \% \mathrm{Pd}-\mathrm{C}(60 \mathrm{mg})$ is added. The mixture is hydrogenated at $1 \mathrm{~atm}$ for $60 \mathrm{~h}$. The catalyst is filtered, and the filtrate is evaporated. The residue is partially purified (silica gel, hexane:ethyl acetate $1: 1)$ and the slightly impure product $(24 \mathrm{mg}, 0.076 \mathrm{mmol})$ is stirred in $5 \%$ methanolic $\mathrm{NaOH}$ overnight. After acidifying with methanolic $\mathrm{HCl}$, the contents are evaporated to dryness and the residue is coupled with piperonylamine using 2 eq of Hunig's base and 1 eq of HATU in dry DMF. After aqueous workup the residue is purified by chromatography (silica gel, ethyl acetate:methanol 98:2) to yield $6 \mathrm{mg}(19 \%)$ 
of the desired product. NMR $\left(\mathrm{CDCl}_{3}\right): 7.80(\mathrm{~s}, 1 \mathrm{H}), 7.10-7.30(\mathrm{~m}, 4 \mathrm{H}), 6.50-6.70(\mathrm{~m}$, $5 \mathrm{H}), 5.90(\mathrm{~s}, 2 \mathrm{H}), 4.20-4.35(\mathrm{~m}, 2 \mathrm{H}), 3.85(\mathrm{bs}, 1 \mathrm{H}), 3.50(\mathrm{t}, 2 \mathrm{H}), 2.95(\mathrm{~d}, 1 \mathrm{H}), 2.35-2.55$ (m, 2H), 1.40-1.90 (m, 6H). MS: $419(\mathrm{M}+\mathrm{H})^{+}$.

N-(1,3-benzodioxol-5-ylmethyl)-1-[6-chloro-2-(1H-imidazol-1-yl)-4pyrimidinyl]-2-piperidineacetamide (18a). NMR (DMSO-d $\left.\mathrm{d}_{6}\right): \delta 8.45(\mathrm{~s}, 1 \mathrm{H}), 8.4$ (br, 1H), $7.85(\mathrm{~s}, 1 \mathrm{H}), 7.05(\mathrm{~s}, 1 \mathrm{H}), 6.85(\mathrm{br}, 1 \mathrm{H}), 6.6(\mathrm{~m}, 3 \mathrm{H}), 5.9(\mathrm{~s}, 2 \mathrm{H}), 4-4.6(\mathrm{~m}, 4 \mathrm{H})$, $3.1(\mathrm{~m}, 1 \mathrm{H}), 2.56(\mathrm{~m}, 2 \mathrm{H}), 1.3-1.7(\mathrm{~m}, 6 \mathrm{H})$. Anal. $\left(\mathrm{C}_{22} \mathrm{H}_{23} \mathrm{~N}_{6} \mathrm{O}_{3} \mathrm{Cl}\right) \mathrm{C}, \mathrm{H}, \mathrm{N}, \mathrm{Cl}$.

\section{N-(1,3-benzodioxol-5-ylmethyl)-1-[2-(1H-imidazol-1-yl)-6-phenyl-4-}

pyrimidinyl]-2-piperidineacetamide (18b): NMR (DMSO-d $\left.\mathrm{d}_{6}\right): \delta 8.5(\mathrm{~s}, 1 \mathrm{H}), 8.4(\mathrm{~s}$, 1H), $8.2(\mathrm{~d}, 1 \mathrm{H}), 7.95(\mathrm{~d}, 2 \mathrm{H}), 7.47(\mathrm{~m}, 2 \mathrm{H}), 7.2(\mathrm{~s}, 1 \mathrm{H}), 7.05(\mathrm{~s}, 1 \mathrm{H}), 6.5 \sim 6.8(\mathrm{~m}, 3$ H), $5.9(\mathrm{~s}, 2 \mathrm{H}), 4 \sim 4.2(\mathrm{~m}, 4 \mathrm{H}), 3.1(\mathrm{~m}, 1 \mathrm{H}), 2.56(\mathrm{~m}, 2 \mathrm{H}), 1.3 \sim 1.7(\mathrm{~m}, 6 \mathrm{H})$. Anal. $\left(\mathrm{C}_{28} \mathrm{H}_{28} \mathrm{~N}_{6} \mathrm{O}_{3} \cdot 0.5 \mathrm{C}_{3} \mathrm{H}_{7} \mathrm{NO} \cdot 0.05 \mathrm{C}_{3} \mathrm{H}_{4} \mathrm{~N}_{2}\right) \mathrm{C}, \mathrm{H}, \mathrm{N}$.

\section{N-(1,3-benzodioxol-5-ylmethyl)-1-[2-(1H-imidazol-1-yl)-6-methyl-4-}

pyrimidinyl]- 2-piperidineacetamide (18c). NMR (DMSO-d 6 ): $\delta 9.6$ (brd, $1 \mathrm{H}), 8.5$ (s, 1H), $8.25(\mathrm{~d}, 1 \mathrm{H}), 7.7(\mathrm{~m}, 2 \mathrm{H}), 6.5 \sim 6.8(\mathrm{~m}, 3 \mathrm{H}), 5.9(\mathrm{~s}, 2 \mathrm{H}), 4 \sim 4.2(\mathrm{~m}, 4 \mathrm{H}), 3.1(\mathrm{~m}, 1$ $\mathrm{H}), 2.6(\mathrm{~m}, 2 \mathrm{H}), 2.2(\mathrm{~s}, 3 \mathrm{H}), 1.3 \sim 1.7(\mathrm{~m}, 6 \mathrm{H})$. Anal. $\left(\mathrm{C}_{23} \mathrm{H}_{26} \mathrm{~N}_{6} \mathrm{O}_{3} \cdot 0.8 \mathrm{H}_{2} \mathrm{O} \cdot 2.4\right.$ $\left.\mathrm{C}_{2} \mathrm{HF}_{3} \mathrm{O}_{2}\right) \mathrm{C}, \mathrm{H}, \mathrm{N}$.

$N$-(1,3-benzodioxol-5-ylmethyl)-1-[2-(1H-imidazol-1-yl)-6-(trifluoromethyl)-4pyrimidinyl]- 2-piperidineacetamide (18d): NMR (DMSO- $\left.\mathrm{d}_{6}\right): \delta 9.4$ (brd, $\left.1 \mathrm{H}\right), 8.5$ (brd, 1H), $8.3(\mathrm{~s}, 1 \mathrm{H}), 7.5(\mathrm{~m}, 2 \mathrm{H}), 6.5 \sim 6.8(\mathrm{~m}, 3 \mathrm{H}), 5.9(\mathrm{~s}, 2 \mathrm{H}), 5.36(\mathrm{~s}, 1 \mathrm{H}), 4.61(\mathrm{~m}$, 1H), $4.02(\mathrm{~m}, 1 \mathrm{H}), 3.1(\mathrm{~m}, 1 \mathrm{H}), 1.3 \sim 1.7(\mathrm{~m}, 6 \mathrm{H})$. Anal. $\left(\mathrm{C}_{23} \mathrm{H}_{23} \mathrm{~F}_{3} \mathrm{~N}_{6} \mathrm{O}_{3} \cdot 0.5 \mathrm{H}_{2} \mathrm{O} \cdot 1.5\right.$ $\left.\mathrm{C}_{2} \mathrm{HF}_{3} \mathrm{O}_{2}\right) \mathrm{C}, \mathrm{H}, \mathrm{N}, \mathrm{F}$. 
$N$-(1,3-benzodioxol-5-ylmethyl)-1-[2,6-di(1H-imidazol-1-yl)-4-pyrimidinyl]- 2piperidineacetamide (18e). NMR (DMSO-d $\left.\mathrm{d}_{6}\right): \delta 10.3(\mathrm{br}, 1 \mathrm{H}), 9.9(\mathrm{~s}, 1 \mathrm{H}), 8.78(\mathrm{~s}, 1$ H), $8.63(\mathrm{~m}, 3 \mathrm{H}), 7.95(\mathrm{~m}, 2 \mathrm{H}), 7.41(\mathrm{~d}, 1 \mathrm{H}), 6.5(\mathrm{~m}, 2 \mathrm{H}), 5.8(\mathrm{~s}, 2 \mathrm{H}), 4.9(\mathrm{~m}, 1 \mathrm{H}), 4.03$ (m, 3H), $3.5(\mathrm{t}, 1 \mathrm{H}), 3.1(\mathrm{~m}, 1 \mathrm{H}), 1.3 \sim 1.7(\mathrm{~m}, 6 \mathrm{H})$. Anal.

$\left(\mathrm{C}_{25} \mathrm{H}_{26} \mathrm{~N}_{8} \mathrm{O}_{3} \cdot 1.2 \mathrm{H}_{2} \mathrm{O} \cdot 3 \mathrm{C}_{2} \mathrm{HF}_{3} \mathrm{O}_{2}\right) \mathrm{C}, \mathrm{H}, \mathrm{N}, \mathrm{F}$.

$N$-[(1,3-benzodioxol-5-yl)methyl]-4-[2-(1H-imidazol-1-yl)-6-methylpyrimidin4-yl]-2-piperazineacetamide (19a). NMR $\left(\mathrm{CDCl}_{3}\right) \delta 8.55$ (s, $\left.1 \mathrm{H}\right), 7.8(\mathrm{~s}, 1 \mathrm{H}), 7.1$ (s, 1 H), $6.75(\mathrm{~m}, 4 \mathrm{H}), 6.25(\mathrm{~s}, 1 \mathrm{H}), 5.95(\mathrm{~s}, 2 \mathrm{H}), 4.4(\mathrm{~m}, 2 \mathrm{H}), 4.35(\mathrm{~m}, 2 \mathrm{H}), 3.2(\mathrm{~m}, 3 \mathrm{H})$, $2.85(\mathrm{~m}, 2 \mathrm{H}), 2.4(\mathrm{~m}, 3 \mathrm{H}), 2.4(\mathrm{~s}, 3 \mathrm{H})$. Anal. $\left(\mathrm{C}_{22} \mathrm{H}_{25} \mathrm{~N}_{7} \mathrm{O}_{3} \cdot 0.1 \mathrm{CH}_{2} \mathrm{Cl}_{2} \cdot 0.8 \mathrm{H}_{2} \mathrm{O}\right) \mathrm{C}, \mathrm{H}, \mathrm{N}$. $N$-[(1,3-benzodioxol-5-yl)methyl]-4-[2-(1H-imidazol-1-yl)-6-methylpyrimidin4-yl]-1-methyl-2-piperazineacetamide (19b). NMR $\left(\mathrm{CDCl}_{3}\right) \delta 8.5(\mathrm{~s}, 1 \mathrm{H}), 7.8(\mathrm{~s}, 1 \mathrm{H})$, $7.7(\mathrm{~m}, 1 \mathrm{H}), 7.05(\mathrm{~s}, 1 \mathrm{H}), 6.75(\mathrm{~m}, 3 \mathrm{H}), 6.2(\mathrm{~s}, 1 \mathrm{H}), 5.9(\mathrm{~s}, 2 \mathrm{H}), 4.35(\mathrm{~m}, 2 \mathrm{H}), 3.9-4.2$ (m, 2 H), $3.25(m, 2 \mathrm{H}), 2.85(\mathrm{~d}, 1 \mathrm{H}), 2.4-2.7(\mathrm{~m}, 4 \mathrm{H}), 2.4(2 \mathrm{~s}, 6 \mathrm{H})$. Anal. $\left(\mathrm{C}_{23} \mathrm{H}_{27} \mathrm{~N}_{7} \mathrm{O}_{3} .0 .2 \mathrm{H}_{2} \mathrm{O}\right) \mathrm{C}, \mathrm{H}, \mathrm{N}$.

$N$-[(1,3-benzodioxol-5-yl)methyl]-4-[2-(1H-imidazol-1-yl)-6-methylpyrimidin4-yl]-1-(phenylmethyl)-2-piperazineacetamide (19c). NMR $\left(\mathrm{CDCl}_{3}\right) \delta 8.5(\mathrm{~s}, 1 \mathrm{H}), 7.8$ (s, $1 \mathrm{H}), 7.2(\mathrm{~m}, 6 \mathrm{H}), 7.1(\mathrm{~s}, 1 \mathrm{H}), 6.75(\mathrm{~m}, 3 \mathrm{H}), 6.22(\mathrm{~s}, 1 \mathrm{H}), 5.97(\mathrm{~s}, 2 \mathrm{H}), 4.4$ (dd, 1 H), $4.3(\mathrm{dd}, 1 \mathrm{H}), 3.95(\mathrm{~d}, 1 \mathrm{H}), 3.8(\mathrm{~m}, 3 \mathrm{H}), 3.6(\mathrm{~m}, 1 \mathrm{H}), 3.45(\mathrm{~d}, 1 \mathrm{H}), 3.15(\mathrm{~m}, 1 \mathrm{H})$, 2.75 (m, $1 \mathrm{H})$, 2.4-2.7 (m, $3 \mathrm{H}), 2.4(\mathrm{~s}, 3 \mathrm{H})$. Anal. $\left(\mathrm{C}_{29} \mathrm{H}_{31} \mathrm{~N}_{7} \mathrm{O}_{3} .0 .1 \mathrm{CH}_{2} \mathrm{Cl}_{2} .0 .4 \mathrm{H}_{2} \mathrm{O}\right) \mathrm{C}$, $\mathrm{H}, \mathrm{N}$.

N-(1,3-benzodioxol-5-ylmethyl)-4-[2-(1H-imidazol-1-yl)-6-methyl-4pyrimidinyl]-1-(methylsulfonyl)-2-piperazineacetamide (19d): NMR (DMSO- $\left.d_{6}\right)$ : $\delta 9.7(\mathrm{~s}, 1 \mathrm{H}), 8.4(\mathrm{~m}, 2 \mathrm{H}), 7.8(\mathrm{~s}, 1 \mathrm{H}), 6.6(\mathrm{~m}, 3 \mathrm{H}), 5.95(\mathrm{~s}, 2 \mathrm{H}), 4.45(\mathrm{~m}, 4 \mathrm{H}), 4.3(\mathrm{~m}$, 
3H), $3.62(\mathrm{~m}, 2 \mathrm{H}), 3.1(\mathrm{~m}, 1 \mathrm{H}), 3(\mathrm{~s}, 3 \mathrm{H}), 2.45(\mathrm{~m}, 3 \mathrm{H}), 2.1(\mathrm{~s}, 3 \mathrm{H})$. Anal.

$\left(\mathrm{C}_{23} \mathrm{H}_{27} \mathrm{~N}_{7} \mathrm{O}_{5} \mathrm{~S} \cdot 0.5 \mathrm{H}_{2} \mathrm{O} \cdot 2.6 \mathrm{C}_{2} \mathrm{HF}_{3} \mathrm{O}_{2}\right) \mathrm{C}, \mathrm{H}, \mathrm{N}$.

N-[(1,3-benzodioxol-5-yl)methyl]-4-[2-(1H-imidazol-1-yl)-6-methylpyrimidin4-yl]-1-(methylcarbonyl)-2-piperazineacetamide (19e). NMR (DMSO- $\left.\mathrm{d}_{6}, 100{ }^{\circ} \mathrm{C}\right)$

$\delta 8.45(\mathrm{~s}, 1 \mathrm{H}), 7.85(\mathrm{~m}, 1 \mathrm{H}), 7.8(\mathrm{~s}, 1 \mathrm{H}), 7.05(\mathrm{~s}, 1 \mathrm{H}), 6.7(\mathrm{~m}, 3 \mathrm{H}), 6.55(\mathrm{~s}, 1 \mathrm{H}), 5.95$ (s, $2 \mathrm{H}), 4.7(\mathrm{~m}, 1 \mathrm{H}), 4.0-4.5(\mathrm{~m}, 5 \mathrm{H}), 3.35(\mathrm{~m}, 1 \mathrm{H}), 3.15(\mathrm{~m}, 1 \mathrm{H}), 2.4(\mathrm{~s}, 3 \mathrm{H}), 2.1(\mathrm{~s}, 3$ H). Anal. (C26H31N7O4.0.2 $\left.\mathrm{CH}_{2} \mathrm{Cl}_{2} \cdot 0.1 \mathrm{H}_{2} \mathrm{O}\right) \mathrm{C}, \mathrm{H}, \mathrm{N}$.

$N$-[(1,3-benzodioxol-5-yl)methyl]-4-[2-(1H-imidazol-1-yl)-6-methylpyrimidin4-yl]-1-[(1-methylethyl)carbonyl]-2-piperazineacetamide (19f). NMR (DMSO-d 6 , 100 $\left.{ }^{\circ} \mathrm{C}\right) \delta 8.45(\mathrm{~s}, 1 \mathrm{H}), 7.85(\mathrm{~m}, 2 \mathrm{H}), 7.05(\mathrm{~s}, 1 \mathrm{H}), 6.7(\mathrm{~m}, 3 \mathrm{H}), 6.55(\mathrm{~s}, 1 \mathrm{H}), 5.95(\mathrm{~s}, 2 \mathrm{H})$, $4.8(\mathrm{~m}, 1 \mathrm{H}), 4.45(\mathrm{~d}, 1 \mathrm{H}), 4.3(\mathrm{~d}, 1 \mathrm{H}), 4.15(\mathrm{~m}, 3 \mathrm{H}), 3.35(\mathrm{dd}, 1 \mathrm{H}), 3.2(\mathrm{~m}, 2 \mathrm{H}), 2.9(\mathrm{~m}$, $1 \mathrm{H}), 2.55(\mathrm{~m}, 1 \mathrm{H}), 2.4(\mathrm{~m}, 1 \mathrm{H}), 2.35(\mathrm{~s}, 3 \mathrm{H}), 1.05(2 \mathrm{~s}, 6 \mathrm{H})$. Anal. $\left(\mathrm{C}_{26} \mathrm{H}_{31} \mathrm{~N}_{7} \mathrm{O}_{4}\right) \mathrm{C}, \mathrm{H}$, N.

2-[2-[(1,3-benzodioxol-5-ylmethyl)amino]-2-oxoethyl]-4-[2-(1H-imidazol-1yl)-6-methyl-4-pyrimidinyl]-1-piperazinecarboxylic acid, methyl ester (19g): NMR (DMSO-d $\left.\mathrm{d}_{6}\right): \delta 9.4(\mathrm{~s}, 1 \mathrm{H}), 8.2(\mathrm{~m}, 2 \mathrm{H}), 7.6(\mathrm{~s}, 1 \mathrm{H}), 6.7(\mathrm{~m}, 3 \mathrm{H}), 5.95(\mathrm{~s}, 2 \mathrm{H}), 4.6(\mathrm{~m}$, 2H), 3.9 4.41 (m, 4H), $3.62(\mathrm{~s}, 3 \mathrm{H}), 3.1 \sim 3.4(\mathrm{~m}, 3 \mathrm{H}), 2.6(\mathrm{~m}, 4 \mathrm{H}), 2.3(\mathrm{~s}, 3 \mathrm{H})$. Anal. $\left(\mathrm{C}_{24} \mathrm{H}_{27} \mathrm{~N}_{7} \mathrm{O}_{5} \cdot 0.5 \mathrm{H}_{2} \mathrm{O} \cdot 1.4 \mathrm{C}_{2} \mathrm{HF}_{3} \mathrm{O}_{2}\right) \mathrm{C}, \mathrm{H}, \mathrm{N}$.

\section{N-[(1,3-benzodioxol-5-yl)methyl]-1-[2-(1H-imidazol-1-yl)-4-pyrimidinyl]-2-}

pyrrolidineacetamide (20a). NMR $\left(\mathrm{CDCl}_{3}\right) \delta 8.5(\mathrm{~s}, 1 \mathrm{H}), 8.1(\mathrm{~d}, 1 \mathrm{H}), 7.8(\mathrm{~s}, 1 \mathrm{H}), 7.0$ (s, $1 \mathrm{H}), 6.7(\mathrm{~m}, 3 \mathrm{H}), 6.1(\mathrm{~m}, 4 \mathrm{H}), 4.7(\mathrm{br} \mathrm{s}, 1 \mathrm{H}), 4.3(\mathrm{~m}, 2 \mathrm{H}), 3.4(\mathrm{~m}, 2 \mathrm{H}), 2.8(\mathrm{br} \mathrm{s}, 1$ H), $2.3(\mathrm{br} \mathrm{s}, 1 \mathrm{H}), 2.1(\mathrm{~m}, 4 \mathrm{H})$. Anal. $\left(\mathrm{C}_{21} \mathrm{H}_{22} \mathrm{~N}_{6} \mathrm{O}_{3} \cdot \mathrm{CH}_{2} \mathrm{Cl}_{2}\right) \mathrm{C}, \mathrm{H}, \mathrm{N}$. 
N-[(1,3-benzodioxol-5-yl)methyl]-1-[2-(1H-imidazol-1-yl)-6-methyl-4-

pyrimidinyl]-2-pyrrolidineacetamide (20b). NMR $\left(\mathrm{CDCl}_{3}\right) \delta 8.4(\mathrm{~m}, 1 \mathrm{H}), 7.7(\mathrm{~m}, 1 \mathrm{H})$, $7.0(\mathrm{~s}, 1 \mathrm{H}), 6.7(\mathrm{~m}, 3 \mathrm{H}), 6.0(\mathrm{~m}, 4 \mathrm{H}), 4.6(\mathrm{br} \mathrm{s}, 1 \mathrm{H}), 4.3(\mathrm{~m}, 2 \mathrm{H}), 3.4(\mathrm{~m}, 2 \mathrm{H}), 2.8(\mathrm{br}$ $\mathrm{s}, 1 \mathrm{H}), 2.2(\mathrm{~m}, 8 \mathrm{H})$. Anal. $\left(\mathrm{C}_{22} \mathrm{H}_{24} \mathrm{~N}_{6} \mathrm{O}_{3} \cdot \mathrm{CH}_{2} \mathrm{Cl}_{2}\right) \mathrm{C}, \mathrm{H}, \mathrm{N}$.

$N$-[(1,3-benzodioxol-5-yl)methyl]-1-[6-ethyl-2-(1H-imidazol-1-yl)-4-

pyrimidinyl]-2-pyrrolidineacetamide (20c). $\operatorname{NMR}\left(\mathrm{CDCl}_{3}\right) \delta 8.6(\mathrm{~s}, 1 \mathrm{H}), 7.8(\mathrm{~s}, 1 \mathrm{H})$, $7.0(\mathrm{~s}, 1 \mathrm{H}), 6.7(\mathrm{~m}, 3 \mathrm{H}), 6.1(\mathrm{~m}, 1 \mathrm{H}), 5.9(\mathrm{~s}, 2 \mathrm{H}), 5.8(\mathrm{~m}, 1 \mathrm{H}), 4.7(\mathrm{br} \mathrm{s}, 1 \mathrm{H}), 4.4(\mathrm{dd}$, $1 \mathrm{H}), 4.3(\mathrm{~m}, 1 \mathrm{H}), 3.4(\mathrm{~m}, 2 \mathrm{H}), 2.8(\mathrm{br} \mathrm{s}, 1 \mathrm{H}), 2.6(\mathrm{q}, 2 \mathrm{H}), 2.4(\mathrm{br} \mathrm{s}, 1 \mathrm{H}), 2.1(\mathrm{~m}, 4 \mathrm{H})$, $1.3(\mathrm{t}, 3 \mathrm{H})$. Anal. $\left(\mathrm{C}_{23} \mathrm{H}_{26} \mathrm{~N}_{6} \mathrm{O}_{3} \cdot \mathrm{CH}_{2} \mathrm{Cl}_{2}\right) \mathrm{C}, \mathrm{H}, \mathrm{N}$.

$N$-[2-(1,3-benzodioxol-5-yl)ethyl]-1-[2-(1H-imidazol-1-yl)-4-pyrimidinyl]-2pyrrolidinecarboxamide (21a). $\operatorname{NMR}\left(\mathrm{CDCl}_{3}\right) \delta 8.4(\mathrm{~s}, 1 \mathrm{H}), 8.2(\mathrm{~d}, 1 \mathrm{H}), 7.7(\mathrm{br} \mathrm{s}, 1$ H), $7.1(\mathrm{~s}, 1 \mathrm{H}), 6.4(\mathrm{~m}, 5 \mathrm{H}), 5.8(\mathrm{~m}, 2 \mathrm{H}), 4.6(\mathrm{br} \mathrm{s}, 1 \mathrm{H}), 3.4(\mathrm{~m}, 4 \mathrm{H}), 2.8(\mathrm{~m}, 2 \mathrm{H}), 2.1$ (m, $4 \mathrm{H})$. Anal. $\left(\mathrm{C}_{21} \mathrm{H}_{22} \mathrm{~N}_{6} \mathrm{O}_{3}\right) \mathrm{C}, \mathrm{H}, \mathrm{N}$.

N-[2-(1,3-benzodioxol-5-yl)ethyl]-1-[2-(1H-imidazol-1-yl)-6-methyl-4pyrimidinyl]-2-pyrrolidinecarboxamide (21b). NMR $\left(\mathrm{CDCl}_{3}\right) \delta 8.5(\mathrm{~s}, 1 \mathrm{H}), 7.7(\mathrm{~s}, 1$ H), $7.1(\mathrm{~s}, 1 \mathrm{H}), 6.5(\mathrm{~m}, 4 \mathrm{H}), 6.1(\mathrm{br} \mathrm{s}, 1 \mathrm{H}), 5.8(\mathrm{~m}, 2 \mathrm{H}), 4.6(\mathrm{br} \mathrm{s}, 1 \mathrm{H}), 3.5(\mathrm{~m}, 4 \mathrm{H})$, $2.6(\mathrm{~m}, 2 \mathrm{H}), 2.4(\mathrm{~m}, 4 \mathrm{H}), 2.1(\mathrm{br} \mathrm{s}, 2 \mathrm{H}), 1.3(\mathrm{~s}, 1 \mathrm{H})$. Anal. $\left(\mathrm{C}_{22} \mathrm{H}_{24} \mathrm{~N}_{6} \mathrm{O}_{3}\right) \mathrm{C}, \mathrm{H}, \mathrm{N}$.

$N$-[(1,3-benzodioxol-5-yl)ethyl]-4-[2-(1H-imidazol-1-yl)-6-ethylpyrimidin-4-yl]2-pyrrolidinecarboxamide (21c). NMR $\left(\mathrm{CDCl}_{3}\right) \delta 8.5(\mathrm{~s}, 1 \mathrm{H}), 7.8(\mathrm{~s}, 1 \mathrm{H}), 7.1(\mathrm{~s}, 1 \mathrm{H})$, $6.5(\mathrm{~m}, 4 \mathrm{H}), 6.1(\mathrm{br} \mathrm{s}, 1 \mathrm{H}), 5.8(\mathrm{~m}, 2 \mathrm{H}), 4.6(\mathrm{br} \mathrm{s}, 1 \mathrm{H}), 3.5(\mathrm{~m}, 4 \mathrm{H}), 2.6(\mathrm{~m}, 4 \mathrm{H}), 2.4$ (br s, 1H), 2.1 (br s, $3 \mathrm{H}), 1.3(\mathrm{t}, 3 \mathrm{H})$. Anal. $\left(\mathrm{C}_{23} \mathrm{H}_{26} \mathrm{~N}_{6} \mathrm{O}_{3}\right) \mathrm{C}, \mathrm{H}, \mathrm{N}$.

Optically active $N$-[(1,3-benzodioxol-5-yl)methyl]-1-[2-(1H-imidazol-1yl)pyrimidin-4-yl]-4-[(methoxy)carbonyl]-2-piperazineacetamide (11d $\left.\mathbf{d}^{*}\right)$. N-[(1,3- 
benzodioxol-5-yl)methyl-4-[(methoxy)carbonyl]-1-[(dimethylethoxy)carbonyl)]piperazine2-acetamide was separated on a chiralpak AD column (Chiral Technologies Inc.) using hexanes/isopropanol (4/1). After separation, the two enantiomers were treated identically by manners previously described to give the final compounds. Initial treatment with trifluoroacetic acid deprotected the piperazine. The piperazine was added to 4-chloro-2-methylsulfonylpyrimidine and subsequent reaction with imidazole gave the title compound. The earlier eluting enantiomer resulted in the more potent final product, which was identified as the S-enantiomer by analysis of the crystal structure.

Assay to determine potency inhibiting NO formation. A172 cells were obtained from the American Type Culture Collection, and were cultured routinely in DMEM without phenol red or sodium pyruvate but containing high glucose (Gibco BRL), supplemented with $10 \%(\mathrm{v} / \mathrm{v})$ fetal bovine serum (Gibco BRL), in a humidified atmosphere of $5 \% \mathrm{CO}_{2}$ in air at $37^{\circ} \mathrm{C}$. Cells were harvested and plated at 100,000 cells/well into 96 -well tissue culture dishes in a total of $100 \mu \mathrm{L}$ of culture medium. 18-24 hours later, inducible nitric oxide synthase (iNOS) activity was induced by the addition of $222 \mathrm{U} / \mathrm{ml}$ human interferon-gamma, $22 \mathrm{ng} / \mathrm{ml}$ of human tumor necrosis factor-alpha, and $2.2 \mathrm{ng} / \mathrm{mL}$ of human interleukin 1- $\beta$. All cytokines were purchased from Boehringer Mannheim. Concomitant with cytokine addition, the appropriate concentration of the compound was also added. Compound stock solutions were prepared in DMSO, and vehicle was added to control wells. Final concentration of DMSO in the incubations was less than $0.2 \%$, and had no influence on iNOS induction or activity measurements. Incubations were continued for 18-24 hours, at which time an aliquot of the culture 
medium was removed and tested for nitrite concentration. A $100 \mu \mathrm{L}$ aliquot of the culture medium was removed and mixed with $150 \mu \mathrm{L}$ of the Griess reagent $(5 \% \mathrm{v} / \mathrm{v}$ phosphoric acid containing $2 \% \mathrm{w} / \mathrm{v}$ sulfanilamide plus $0.2 \% \mathrm{w} / \mathrm{v}$ naphthylethylenediamine) in a separate 96-well plate. The plates were read within 15 $\min$ at $550 \mathrm{~nm}$ in a SpectraMax spectrophotometer. The inhibition of NO formation by compound resulted in a decrease in the OD550 of the medium. $\mathrm{IC}_{50}$ values were calculated from a log-logit analysis of the data. Inhibition curves with Hill slopes of less than 0.5 or greater than 1.5 were rejected. Control experiments showed that no significant conversion of nitrite to nitrate occurred over the course of an experiment. Cells incubated in the absence of cytokines produced no measurable nitrite.

Assays to determine selectivity. BSC-1 cells (American Type Culture Collection) were maintained in DMEM containing $10 \%$ fetal bovine serum. Cells were plated into 96-well tissue culture plates at 30,000 cells per well. After six hours, recombinant vaccinia virus strains encoding human inducible, endothelial and neuronal NOS isoforms were added, along with inhibitor or vehicle. After $17 \mathrm{hr}$ medium was aspirated, and $20 \mu \mathrm{l}$ of $40 \mathrm{mM}$ Tris $\mathrm{pH} 7.5$ containing $0.1 \% \mathrm{NP}-40,5 \mathrm{mg} / \mathrm{ml}$ aproitinin, 1 $\mu \mathrm{g} / \mathrm{ml}$ leupeptin, $1 \mu \mathrm{g} / \mathrm{ml}$ pepstatin and $24 \mu \mathrm{g} / \mathrm{ml}$ of Pefabloc SC was added; the plates were then frozen at $-80^{\circ} \mathrm{C}$. NOS activity in cell lysates was determined by measuring the conversion of arginine into citrulline. The assay mixture contained $40 \mathrm{mM}$ Tris $\mathrm{pH}$ 7.5, $3 \mathrm{mM}$ dithiothreitol (DTT), $4 \mu \mathrm{M}$ each of $\mathrm{H}_{4} \mathrm{~B}, \mathrm{FAD}$ and $\mathrm{FMN}, 0.5 \mu \mathrm{M}$ calmodulin, 15 $\mathrm{mM}$ calcium chloride, $1 \mathrm{mM}$ NADPH and $3 \mu \mathrm{M}\left[{ }^{14} \mathrm{C}\right]$-arginine $(300 \mathrm{Ci} / \mathrm{mol})$. NOS activity in Superdex 200 fractions was measured using the same protocol, except with $4 \mu \mathrm{M}$ $\left[{ }^{14} \mathrm{C}\right]$-arginine and $16 \mu \mathrm{M}$ unlabeled arginine in the assay mixture. 
Rat adjuvant arthritis model. ${ }^{22,23}$ Adult male Lewis rats were injected with 0.1 $\mathrm{ml}$ Mycobacterium butyricum in incomplete Freund's adjuvant (10 mg/ml, intradermally) into the proximal quarter of the tail. Drug treatment started on the day following immunization. Compound $(30,10$, and $3 \mathrm{mg} / \mathrm{kg})$ or vehicle was administered subcutaneously twice daily (12 hour intervals). Naive rats received no treatment. Rats were weighed and observed for clinical signs of arthritis 3 times per week. All rats were sacrificed 34-35 days after immunization. Each dosing group consisted of ten animals. Clinical scoring was done on a scale of 0-4 for each limb, with increasing degrees of redness, gross swelling and distortion of the paw, and joint fusion. The sum of these scores for each limb was totaled and was designated as the clinical score. Radiological (X-ray) scoring was done by grading both hind limbs of the sacrificed animals on a scale of 0-3 for each of the following parameters: soft tissue swelling, cartilage loss, erosion, and heterotopic ossification. The sum of these scores for each limb was totaled and was designated as the radiological score.

Supporting Information Available: Elemental analyses. This material is available free of charge via the internet at http://pubs.acs.org. 


\section{References}

${ }^{1}$ Parkinson, J.F.; Devlin, J.J.; Phillips, G.B. Nitric oxide synthase inhibitors. Endothelial Cell Res. Ser. 1999, 505-521.

${ }^{2}$ Salerno, I.; Sorrenti, V.; Di Giacomo, C.; Romeo, G.; Siracusa, M.A. Progress in the development of selective nitric oxide synthase inhibitors, Curr. Pharma. Des. 2002, 8, 177-200.

${ }^{3}$ Proskuryakov, S.V; Konoplyannikov, A.G.; Skvortsov, V.G.; Mandrugin A.A.; Fedoseev, V.M. Structure and activity of NO synthase inhibitors specific to the Larginine binding site. Biochem. (Moscow) 2005, 70, 8-23.

${ }^{4}$ Wolff, D.J.; Gribin, B.J. Interferon-gamma-inducible murine macrophage nitric oxide synthase: studies on the mechanism of inhibition by imidazole agents. Arch. Biochem. Biophys. 1994, 311, 293-299.

${ }^{5}$ Chabin, R. M.; McCauley, E.; Calaycay, J.R.; Kelly, T.M.; MacNaul, K.L.; Wolfe, G.C.; Hutchinson, N.I.; Madhusudanaraju, S.; Schmidt, J.A.; Kozarich, J.W. Wong, K.K. Active-site structure analysis of recombinant human inducible nitric oxide synthase using imidazole. Biochemistry 1996, 35, 9567-75

${ }^{6}$ Hoelscher, P.; Rehwinkel, H.; Burton, G.; Phillips, G.; Parkinson, J. New and known phenyl and pyridyl imidazole derivatives are nitrogen monoxide synthase inhibitors used to treat neurodegenerative, autoimmune, inflammatory, and circulatory disease. WO 9715555.

${ }^{7}$ Ohlmeyer, M. H. J.; Swanson, R.N.; Dillard, L.W.; Reader, J.C.; Asouline, G.; Kobayashi, R.; Wigler, M.; Still, W.C. Complex synthetic chemical libraries indexed with molecular tags. Proc. Natl. Acad. Sci. 1993, 90, 10922-26. 
${ }^{8}$ McMillan, K.; Adler, M.; Auld, D.S.; Baldwin, J.J.; Blasko, E.; Browne, L.J.; Chelsky, D.; Davey, D.; Dolle, R.E.; Eagan, K.A.; Erickson, S.; Feldman, R.I.; Glaser, C.; Mallari, C.; Morrissey, M.M.; Ohlmeyer, M.H.J.; Pan, G.; Parkinson, J.F.; Phillips, G.B.; Polokoff, M.A.; Sigal, N.A.; Vergona, R.; Whitlow, M.; Young, T.; Devlin,'J.J. Allosteric inhibitors of inducible nitric oxide synthase dimerization discovered via combinatorial chemistry. Proc. Natl. Acad. Sci., 2000, 97, 1506-1511.

${ }^{9}$ Sennequier, N.; Wolan, D.; Stuehr, D.J. Antifungal imidazoles block assembly of inducible NO synthase into an active dimer J. Bio. Chem. 1999, 274, 930-938.

${ }^{10}$ Ohtsuka, M.; Konno, F.; Honda, H.; Oikawa, T.; Ishikawa, M.; Iwase, N.; Isomae, K.; Ishii, F.; Hemmi, H.; Sato, S. PPA250 [3-(2,4-Difluorophenyl)-6-\{2-[4-(1H-imidazol-1ylmethyl) Phenoxy]ethoxy\}-2-phenylpyridine], a novel orally effective inhibitor of the dimerization of inducible nitric-oxide synthase, exhibits an anti-inflammatory effect in animal models of chronic arthritis. J. Pharmacol. Exp. Ther. 2002, 303, 52-57. ${ }^{11}$ Chida, N.; Hirasawa, Y.; Ohkawa, T.; Ishii, Y.; Sudo, U.; Tamura, K.; Mutoh, S. Pharmacological profile of FR260330, a novel orally active inducible nitric oxide synthase inhibitor. Eur. J. Pharm. 2005, 509, 71-6.

${ }^{12}$ Blasko, E.; Glaser, C.B.; Devlin, J.J.; Xia, W.; Feldman, R.I.; Polokoff, M.A.; Phillips, G.B.; Whitlow, M.; Auld, D.S.; McMillan, K.; Ghosh, S.; Stuehr, D.J.; Parkinson, J.F. Mechanistic studies with potent and selective inducible nitric-oxide synthase dimerization inhibitors. J. Biol. Chem. 2002, 277, 295-302.

${ }^{13}$ Afonso, A.; Baldwin, J. J.; Doll, R. J.; Li, G.; Mallams, A. K.; Njoroge, F. G.; Rane, D. F.; Reader, J. C.; Rossman, R. R. Preparation of heterocyclic tricyclic compounds 
useful for inhibition of g-protein function and for treatment of cell proliferative diseases. W09631478.

${ }^{14}$ Van den Branden, S.; Compernolle, F.; Hoorneaert, G.J. Synthesis of lactam and ketone precursors of 2,7-substituted octahydropyrrolo[1,2-a]pyrazines and octahydro2H-pyrido[1,2-a]pyrazines. J. Chem. Soc. Perkin Trans. 1 1992, 1035-1042.

${ }^{15}$ The $\mathrm{IC}_{50}$ reported for the assays in tables 1-7 are based on an average of at least two separate experiments. The values determined in the vaccinia assays are referred to as vaccinia in the tables. The values determined in the tetracycline assay are referred to as tet in the tables. The selectivity ratios were calculated by dividing the $\mathrm{IC}_{50}$ 's from either the ecNOS or bcNOS assay by the $\mathrm{IC}_{50}$ from the iNOS assay in the same system and is referred to as e/i or b/i, respectively. For all compounds that had an $\mathrm{IC}_{50}>10 \mu \mathrm{M}$ in one of the selectivity assays, $10 \mu \mathrm{M}$ was used in the ratio calculation.

${ }^{16}$ Bredt, D. S.; Snyder, S. H. Isolation of NOS, a calmodulin-requiring enzyme. Proc. Natl. Acad. Sci. 1990, 87, 682-685.

${ }^{17}$ The structure of the 4-methoxyphenethylamide analog (instead of the piperonylamide of $19 d$ ) was determined by X-ray and the corresponding stereochemistry of $19 d$ is inferred.

${ }^{18}$ Li, H., Raman, C. S., Glaser, C. B., Blasko, E., Young, T. A., Parkinson, J. F., Whitlow, M., and Poulos, T. L. Crystal structures of zinc-free and -bound heme domain of human iNOS. J. Biol. Chem. 1999, 274, 21276-84.

${ }^{19}$ Arnaiz, D. O.; Baldwin, J. J.; Davey, D. D.; Devlin, J. J.; Dolle, R. E., III; Erickson, S. D.; McMillan, K.; Morrissey, M. M.; Ohlmeyer, M. H. J.; Pan, G.; Paradkar, V. M.; Parkinson, J.; Phillips, G. B.; Ye, B.; Zhao, Z. N-Heterocyclic derivatives as NOS 
inhibitors. US6,849,739.

${ }^{20}$ Johnson, A. L.; Kauer, J. C.; Sharma, D. C.; Dorfman, R. I. Synthesis of 1arylimidazoles, a new class of steroid hydroxylation inhibitors. J. Med. Chem. 1969, 12, 1024-1028.

${ }^{21}$ Lambert, P. H.; Vaultier, M.; Carrie, R. Application of the intramolecular aza-Wittig reaction to the synthesis of vinylogous urethanes and amides. J. Org. Chem. 1985, 50, $5352-5356$.

${ }^{22}$ Pearson, C.M. Development of arthritis, periarthritis and periostitis in rats given adjuvants. Proc. Soc. Exp. Biol. Med. 1956, 91, 95-101

${ }^{23}$ Ackerman, N.R.; Rooks, W.H.; Shott, L.; Genant, H.; Maloney, P.; West. E. Effects of naproxen on connective tissue changes in the adjuvant arthritic rat. Arth. and Rheum. $1979,22,1365-1374$ 
Table $1 .^{15}$ Substitution at the 4-position of the piperazine<smiles>[R]N1CCN(c2ccnc(-n3ccnc3)n2)C(CC(=O)NCc2ccc3c(c2)OCO3)C1</smiles>

11

\begin{tabular}{|c|c|c|c|c|c|}
\hline \multirow[t]{2}{*}{ cmpd } & \multirow[t]{2}{*}{$\mathrm{R}^{2}$} & \multirow{2}{*}{$\begin{array}{l}\text { A172 } \\
\text { IC50 } \\
(\mathrm{nM})\end{array}$} & \multirow{2}{*}{$\begin{array}{c}\text { vaccinia } \\
{\text { IC } 50^{\mathrm{a}}} \\
\text { (nM) }\end{array}$} & \multicolumn{2}{|c|}{$\begin{array}{c}\text { Vaccinia } \\
\text { selec ratio }\end{array}$} \\
\hline & & & & $\mathrm{b} / \mathrm{i}$ & $\mathrm{e} / \mathrm{i}$ \\
\hline$a$ & $\mathrm{COCH}_{3}$ & 1 & 320 & 3 & $>10$ \\
\hline $\mathrm{b}$ & $\mathrm{CH}_{2} \mathrm{Ph}$ & 1 & 13 & 7 & 770 \\
\hline c & $\mathrm{COPh}$ & 0.5 & 85 & 4 & 220 \\
\hline d & $\mathrm{COOCH}_{3}$ & 0.38 & 24 & 5 & 1700 \\
\hline e & $\mathrm{CONHCH}_{3}$ & 1 & 450 & 4 & $>250$ \\
\hline$f$ & $\mathrm{SO}_{2} \mathrm{CH}_{3}$ & 0.7 & 74 & 12 & $>1000$ \\
\hline$g$ & $\mathrm{H}$ & 0.55 & 70 & 7 & 1200 \\
\hline $\mathrm{h}$ & $\mathrm{CH}_{3}$ & 0.48 & 11 & 2 & 1300 \\
\hline $\mathrm{i}$ & $\mathrm{CH}_{2}$-1-naphthalene & 69 & 120 & 7 & 40 \\
\hline j & CONHPh & 0.87 & 25 & 3 & 350 \\
\hline $\mathrm{k}$ & CONHBn & 0.96 & 72 & 4 & 490 \\
\hline 1 & $\mathrm{SO}_{2} \mathrm{Ph}$ & 2.7 & 34 & 9 & 1100 \\
\hline $\mathrm{m}$ & $\mathrm{CH}_{2}$ Furan & 0.58 & 13 & 2 & 1100 \\
\hline $\mathrm{n}$ & $\mathrm{COCH}_{2} \mathrm{OBn}$ & 0.50 & 28 & 11 & 1220 \\
\hline 0 & CO-2-furan & 0.67 & 48 & 6 & 1000 \\
\hline$p$ & $\mathrm{CO}_{2} \mathrm{Ph}$ & 1.4 & 16 & 5 & 700 \\
\hline$q$ & COOBn & 0.8 & 18 & 7 & 660 \\
\hline$r$ & $\left(\mathrm{CH}_{2}\right)_{2} \mathrm{CHMe}_{2}$ & 1.0 & 10 & 6 & 1000 \\
\hline $\mathrm{s}$ & COOiPr & 1.0 & 24 & 4 & 800 \\
\hline $\mathrm{t}$ & 6-F-2-pyridine & 0.28 & 10 & 6 & 850 \\
\hline $\mathrm{u}$ & $\mathrm{CH}_{2} \mathrm{COOEt}$ & 0.93 & 4.9 & 5 & 1700 \\
\hline v & $\mathrm{C}(=\mathrm{NH}) \mathrm{Me}$ & 33 & 370 & $>10$ & 350 \\
\hline w & Dansyl & 1.1 & NT & NT & NT \\
\hline
\end{tabular}


Table $2 .{ }^{15}$ Data illustrating differences of the central aromatic ring

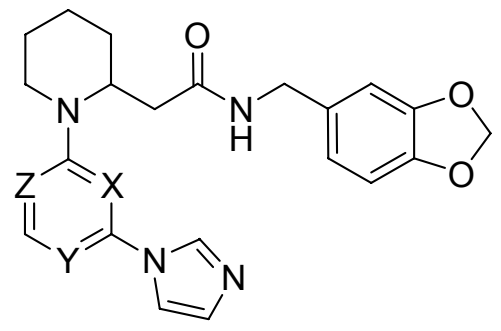

12a,15-17

\begin{tabular}{||c|c|c|c|c|c|c|c||}
\hline cmpd & $\mathbf{X}$ & $\mathrm{Y}$ & $\mathbf{Z}$ & $\mathrm{A} 172$ & Vaccinia & \multicolumn{2}{|c|}{$\begin{array}{c}\text { Selectivity } \\
\text { Ratio }^{\mathrm{a}}\end{array}$} \\
\hline $\mathbf{1 2 a}$ & $\mathrm{N}$ & $\mathrm{N}$ & $\mathrm{CH}$ & 0.5 & 7 & 5 & 520 \\
\hline 15 & $\mathrm{~N}$ & $\mathrm{CH}$ & $\mathrm{N}$ & 52 & 220 & 6 & $>500$ \\
\hline $\mathbf{1 6}$ & $\mathrm{CH}$ & $\mathrm{N}$ & $\mathrm{N}$ & 10 & 100 & 19 & $>1000$ \\
\hline $\mathbf{1 7}$ & $\mathrm{CH}$ & $\mathrm{CH}$ & $\mathrm{CH}$ & 77 & $\mathrm{NT}$ & $\mathrm{NT}$ & $\mathrm{NT}$ \\
\hline
\end{tabular}

${ }^{\mathrm{a}} \mathrm{NT}=$ Not tested 
Table 3. ${ }^{15}$ Variation of the amide moiety<smiles>[R1]NC(=O)CC1CCCCN1c1ccnc(-n2ccnc2)n1</smiles>

12

\begin{tabular}{|c|c|c|c|c|c|}
\hline & $\mathrm{R}^{1}$ & $\begin{array}{l}\text { A172 } \\
\text { IC50 }\end{array}$ & $\begin{array}{c}\text { vaccinia } \\
\mathrm{IC}_{5} 0^{\mathrm{a}}\end{array}$ & $\begin{array}{r}\text { vac } \\
\text { selec }\end{array}$ & $\begin{array}{l}\text { cinia } \\
\text { ratio }^{a}\end{array}$ \\
\hline & & $(\mathrm{nM})$ & $(\mathrm{nM})$ & $\mathrm{b} / \mathrm{i}$ & $\mathrm{e} / \mathrm{i}$ \\
\hline $\mathbf{a}$ & $\mathrm{CH}_{2}$ Benzodioxolane & 0.5 & 7 & 5 & 520 \\
\hline b & $\mathrm{CH}_{2} \mathrm{Ph}-4-\mathrm{OCH}_{3}$ & 0.8 & 23 & 2 & 200 \\
\hline c & $\mathrm{CH}_{2} \mathrm{Ph}-3-\mathrm{OCH}_{3}$ & 3.7 & 230 & 4 & $>430$ \\
\hline d & $\mathrm{CH}_{2} \mathrm{Ph}-2-\mathrm{OCH}_{3}$ & 283 & 500 & 56 & $>200$ \\
\hline e & $\mathrm{CH}_{2} \mathrm{Ph}-3,4-\mathrm{OCH}_{3}$ & 1.5 & 110 & 1 & 900 \\
\hline $\mathbf{f}$ & $\mathrm{CH}_{2} \mathrm{Ph}-3,4,5-\mathrm{OCH}_{3}$ & $>100$ & NT & NT & NT \\
\hline $\mathbf{g}$ & $\mathrm{CH}_{2} \mathrm{Ph}$ & 25 & 440 & 6 & 90 \\
\hline $\mathbf{h}$ & $\mathrm{CH}_{2} \mathrm{Ph}-4-\mathrm{Cl}$ & 5.7 & 160 & 8 & 270 \\
\hline $\mathbf{i}$ & $\mathrm{CH}_{2} \mathrm{Ph}-4-\mathrm{F}$ & 3.0 & 210 & 5 & 490 \\
\hline j & $\mathrm{CH}_{2} \mathrm{Ph}-4-\mathrm{OCF}_{3}$ & 19 & 140 & 5 & 220 \\
\hline $\mathbf{k}$ & $\mathrm{CH}_{2} \mathrm{Ph}-4-\mathrm{CH}_{3}$ & 23 & 270 & 3 & 48 \\
\hline $\mathbf{I}$ & $\mathrm{CH}_{2} \mathrm{Ph}-4-\mathrm{NH}_{2}$ & 270 & 850 & $>12$ & 120 \\
\hline $\mathbf{m}$ & $\mathrm{CH}_{2} \mathrm{Ph}-4-\mathrm{NHSO}_{2} \mathrm{CH}_{3}$ & $>100$ & $>1000$ & & \\
\hline $\mathbf{n}$ & $\mathrm{CH}_{2} \mathrm{Ph}-4-\mathrm{N}\left(\mathrm{CH}_{3}\right)_{2}$ & 66 & 245 & 29 & 86 \\
\hline 0 & $\mathrm{CH}_{2} \mathrm{Ph}-4-\mathrm{CF}_{3}$ & 150 & 260 & 3 & 70 \\
\hline$p$ & $\mathrm{CH}_{2} \mathrm{Ph}-4-\mathrm{CN}$ & $>100$ & $>1000$ & & \\
\hline$q$ & $\mathrm{CH}_{2} \mathrm{Ph}-4-\mathrm{NO}_{2}$ & 168 & 940 & $>10$ & 74 \\
\hline$r$ & $\mathrm{CH}_{2} \mathrm{Ph}-4-\mathrm{SO}_{2} \mathrm{NH}_{2}$ & $>10000$ & $>330$ & & \\
\hline $\mathbf{s}$ & $\mathrm{CH}_{2} \mathrm{Ph}-4-\mathrm{SO}_{2} \mathrm{CH}_{3}$ & 17 & 940 & $>13$ & 110 \\
\hline $\mathbf{t}$ & $\mathrm{CH}_{2}$-2-Furan & 63 & 260 & 13 & 140 \\
\hline $\mathbf{u}$ & $\mathrm{CH}_{2}$-2-Pyridine & 539 & NT & NT & NT \\
\hline $\mathbf{v}$ & $\left(\mathrm{N}-\mathrm{CH}_{3}\right)-\mathrm{CH}_{2} \mathrm{Ph}$ & 885 & NT & NT & NT \\
\hline $\mathbf{w}$ & $\mathrm{CHPh}_{2}$ & 1805 & NT & NT & NT \\
\hline
\end{tabular}




\begin{tabular}{||c|c|c|c|c|c||}
\hline \hline $\mathbf{x}$ & $\mathrm{CH}_{3}$ & $>100$ & & & \\
\hline $\mathbf{y}$ & 2-Benzimidazole & 11 & 1100 & 47 & 16 \\
\hline $\mathbf{z}$ & Benzodioxolane & $>100$ & $\mathrm{NT}$ & $\mathrm{NT}$ & $\mathrm{NT}$ \\
\hline $\mathbf{a a}$ & $\mathrm{Ph}-3,4-\mathrm{OCH}_{3}$ & 66 & 1800 & 1 & $>55$ \\
\hline bb & $\left(\mathrm{CH}_{2}\right)_{2} \mathrm{Ph3}_{4}-\mathrm{OCH}_{3}$ & 12 & 680 & 1 & 120 \\
\hline cc & $\left(\mathrm{CH}_{2}\right)_{2} \mathrm{Ph}-4-\mathrm{OCH}_{3}$ & 3.5 & 42 & 8 & $>1000$ \\
\hline
\end{tabular}

${ }^{a} \mathrm{NT}=$ Not tested 
Table $4 .{ }^{15}$ Variation of the 6 -substituent of the pyrimidine<smiles>[R]c1cc(N2CCCCC2CC(=O)NCc2ccc3c(c2)OCO3)nc(-n2ccnc2)n1</smiles>

\section{8}

\begin{tabular}{||c|c|c|c|c|c||}
\hline \hline cmpd & $\mathrm{R}^{3}$ & $\mathrm{~A} 172$ & vaccinia & \multicolumn{2}{|c||}{ vaccinia } \\
selec ratio \\
\end{tabular}


Table 5. ${ }^{15}$ Piperazine regioisomers<smiles>[R]N1CCN(c2cc(C)nc(-n3ccnc3)n2)CC1CC(=O)NCc1ccc2c(c1)OCO2</smiles>

19

\begin{tabular}{|c|c|c|c|c|c|}
\hline cmpd & $\mathrm{R}^{2}$ & $\begin{array}{l}\mathrm{A} 172 \\
\mathrm{I} \mathrm{C}_{50} \\
(\mathrm{nM})\end{array}$ & $\begin{array}{c}\text { Vaccinia } \\
\text { IC50 } \\
\text { (nM) }\end{array}$ & $\begin{array}{l}\text { vac } \\
\text { selec } \\
\text { b/i }\end{array}$ & $\begin{array}{l}\text { inia } \\
\text { ratio } \\
\text { e/i }\end{array}$ \\
\hline a & $\mathrm{H}$ & 100 & $>1000$ & & \\
\hline $\mathrm{b}$ & $\mathrm{CH}_{3}$ & 12 & 340 & 72 & $>350$ \\
\hline c & $\mathrm{Bn}$ & 25 & 160 & 130 & 350 \\
\hline d & $\mathrm{SO}_{2} \mathrm{CH}_{3}$ & 12 & $>1000$ & & \\
\hline e & $A c$ & 8.5 & 340 & $>32$ & $>320$ \\
\hline$f$ & $\mathrm{COCH}\left(\mathrm{CH}_{3}\right)_{2}$ & 1.1 & 80 & 80 & $>850$ \\
\hline $\mathrm{g}$ & $\mathrm{CO}_{2} \mathrm{CH}_{3}$ & 5.4 & 420 & 50 & $>200$ \\
\hline
\end{tabular}

Table 6. ${ }^{15}$ Comparison of enantiomers

\begin{tabular}{|c|c|c|c|c|c|c|c|}
\hline & $\begin{array}{l}\text { A172 } \\
\text { IC50 }\end{array}$ & $\begin{array}{c}\text { Vaccinia } \\
\text { IC50 }\end{array}$ & \multicolumn{2}{|c|}{$\begin{array}{l}\text { vaccinia } \\
\text { selec ratio }\end{array}$} & $\begin{array}{c}\text { tet } \\
\mathrm{IC}_{50} \mathrm{a}^{\mathrm{a}}\end{array}$ & \multicolumn{2}{|c|}{$\begin{array}{c}\text { tet } \\
\text { selec ratio }\end{array}$} \\
\hline & $(\mathrm{nM})$ & $(\mathrm{nM})$ & $\mathrm{b} / \mathrm{i}$ & $\mathrm{e} / \mathrm{i}$ & $(\mathrm{nM})$ & $\mathrm{b} / \mathrm{i}$ & $\mathrm{e} / \mathrm{i}$ \\
\hline $11 d$ & 0.38 & 24 & 5 & 1700 & 12 & 25 & 82 \\
\hline $11 d-(S)$ & 0.24 & 18 & 6 & 1100 & 10 & 16 & 32 \\
\hline $11 \mathrm{~d}-(\mathrm{R})$ & 34 & $>1000$ & & & NT & NT & NT \\
\hline $19 f$ & 1.1 & 80 & 46 & 118 & 46 & 120 & 240 \\
\hline $19 f-(R)$ & 0.75 & 350 & 29 & $>400$ & 130 & 80 & 74 \\
\hline $19 \mathrm{f}-(\mathrm{S})$ & 300 & $>1000$ & & & NT & NT & NT \\
\hline
\end{tabular}

${ }^{\mathrm{a}} \mathrm{NT}=$ Not tested 
Table $7 .{ }^{15}$ Pyrrolidine analogs arising from d-proline<smiles>[R]c1cc(N2CCC[C@H]2CC(=O)NCc2ccc3c(c2)OCO3)nc(-n2ccnc2)n1</smiles>

20<smiles>[R]Nc1cc(N2CCC[C@H]2C(=O)NCCc2ccc3c(c2)OCO3)nc(-n2ccnc2)n1</smiles>

21

\begin{tabular}{|c|c|c|c|c|c|c|c|c|}
\hline & \multirow[t]{2}{*}{$\mathrm{R}^{3}$} & \multirow{2}{*}{$\begin{array}{l}\text { A172 } \\
\text { IC50 } \\
(\mathrm{nM}) \\
\end{array}$} & \multirow{2}{*}{$\begin{array}{c}\text { tet } \\
\text { IC } 50^{\mathrm{a}} \\
(\mathrm{nM}) \\
\end{array}$} & \multicolumn{2}{|c|}{$\begin{array}{c}\text { tet } \\
\text { selec ratio }\end{array}$} & \multirow{2}{*}{$\begin{array}{r}\text { vac } \\
\text { IC50 } \\
\text { (nM) } \\
\end{array}$} & \multicolumn{2}{|c|}{$\begin{array}{c}\text { vaccinia } \\
\text { selec ratio }\end{array}$} \\
\hline & & & & $\mathrm{b} / \mathrm{i}$ & $\mathrm{e} / \mathrm{i}$ & & $\mathrm{b} / \mathrm{i}$ & $\mathrm{e} / \mathrm{i}$ \\
\hline $20 a$ & $\mathrm{H}$ & 0.28 & 5.5 & 6 & 47 & 5.6 & 5 & 2900 \\
\hline $20 \mathrm{~b}$ & $\mathrm{Me}$ & 0.12 & 4.5 & 27 & 91 & 5.9 & 8 & 1000 \\
\hline $20 \mathrm{c}$ & $\mathrm{Et}$ & 0.13 & 7.1 & 18 & 65 & 7.5 & 15 & 7800 \\
\hline $21 a$ & $\mathrm{H}$ & 0.48 & 11 & 74 & 180 & 25 & 19 & $>2000$ \\
\hline $21 b$ & $\mathrm{Me}$ & 0.29 & 14 & 330 & 540 & 20 & 62 & $>5000$ \\
\hline $21 b^{*}$ & $\mathrm{Me}$ & 6400 & NT & NT & NT & NT & NT & NT \\
\hline $21 \mathrm{c}$ & $\mathrm{Et}$ & 0.52 & 16 & 280 & 170 & 25 & 67 & $>3800$ \\
\hline
\end{tabular}

*arose from L-proline. ${ }^{\mathrm{a}} \mathrm{NT}=$ Not tested 


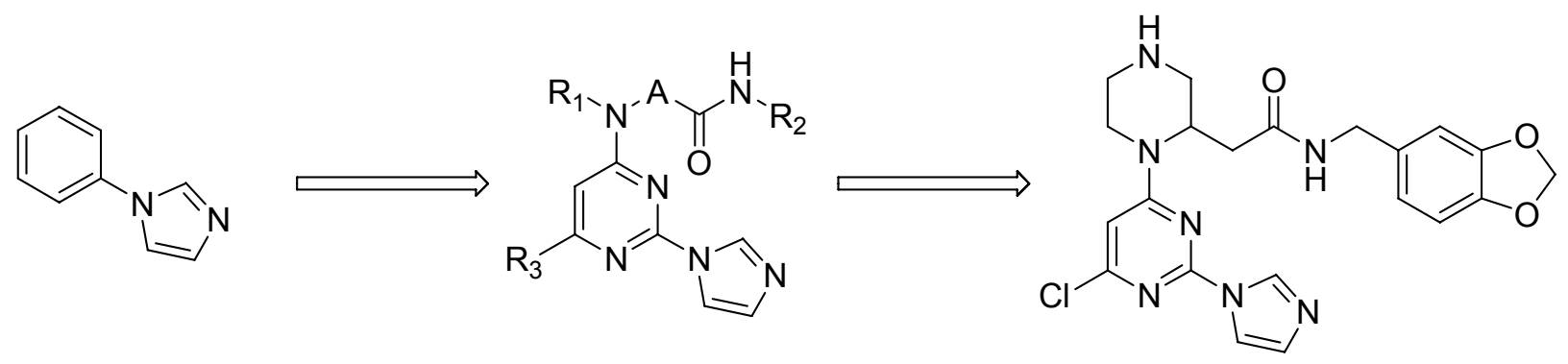

Figure 1. Discovery of dimerization inhibitors<smiles>[R]NC(=O)CC1CN([R])CCN1c1cc([R])nc(-n2ccnc2)n1</smiles>

Figure 2. General optimization strategy<smiles>[X]CC1CCCN1c1ccnc(-n2ccnc2)n1</smiles><smiles>O=C(CC1CCCCCN1c1ccnc(-n2ccnc2)n1)NCc1ccc2c(c1)OCO2</smiles>

$$
\begin{array}{lll}
X=\mathrm{NH} & 11 \mathrm{~g} ; & 0.55 \mathrm{nM} \\
\mathrm{X}=\mathrm{CH}_{2} & \mathbf{1 2 \mathrm { a }} ; & 0.5 \mathrm{nM} \\
\mathrm{X}=\mathrm{O} & \mathbf{1 3} ; & 0.5 \mathrm{nM}
\end{array}
$$$$
\text { 14; } 2 \mathrm{nM}
$$

Figure 3. Comparison of piperazine alternatives in the A172 assay 
A

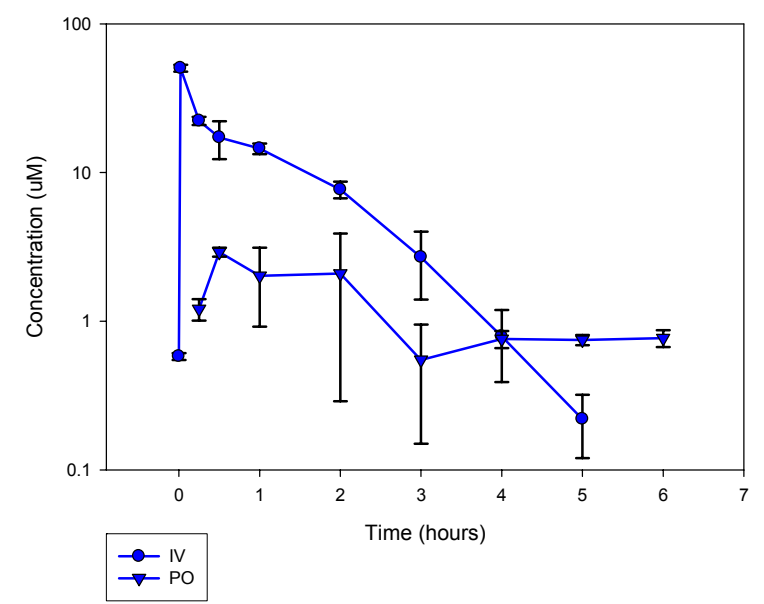

B

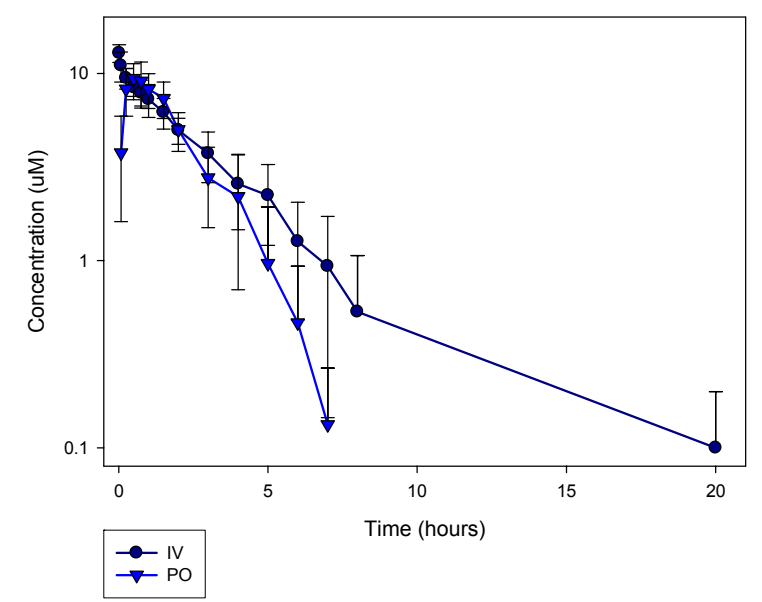

Figure 4. $A$ : $P K$ profile in rats. Error bars represent \pm S.E.M., $n=3$ rats per route. $B$ : PK profile in dogs. Error bars represent \pm S.E.M., $n=3$ dogs per route

A

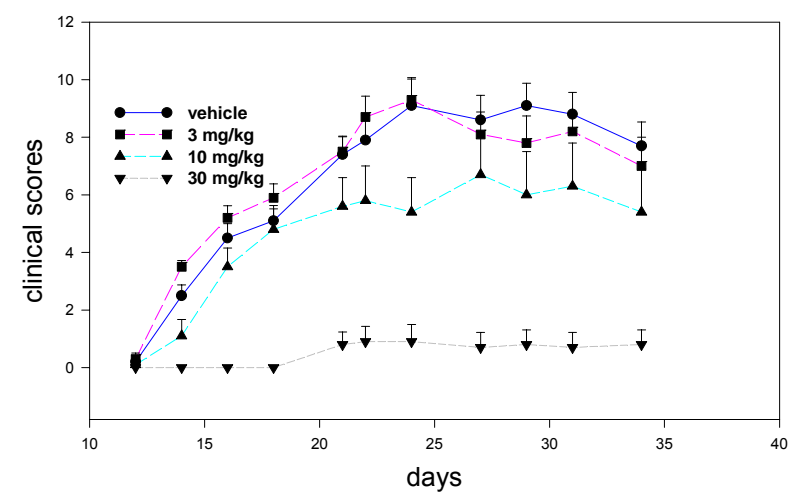

B

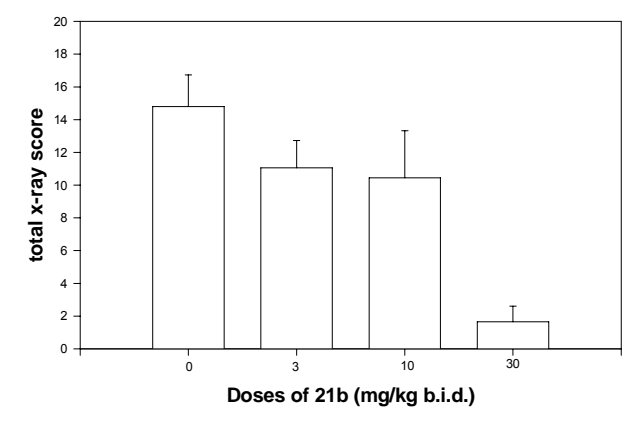

Figure 5. Effects of $\mathbf{2 1 b}$ in a rat adjuvant induced arthritis model. A) Clinical scoring: Each limb was graded on a scale of 0-4 for, with increasing degrees of redness, gross swelling and distortion of the paw, and joint fusion. The sum of the scores for each limb was totaled and designated as the clinical score. B) Radiological scoring: Both hind limbs were graded on a scale of 0-3 for each of the following parameters: soft tissue swelling, cartilage loss, erosion, and heterotopic ossification. The sum of these scores for each limb was totaled and was designated as the radiological score. 


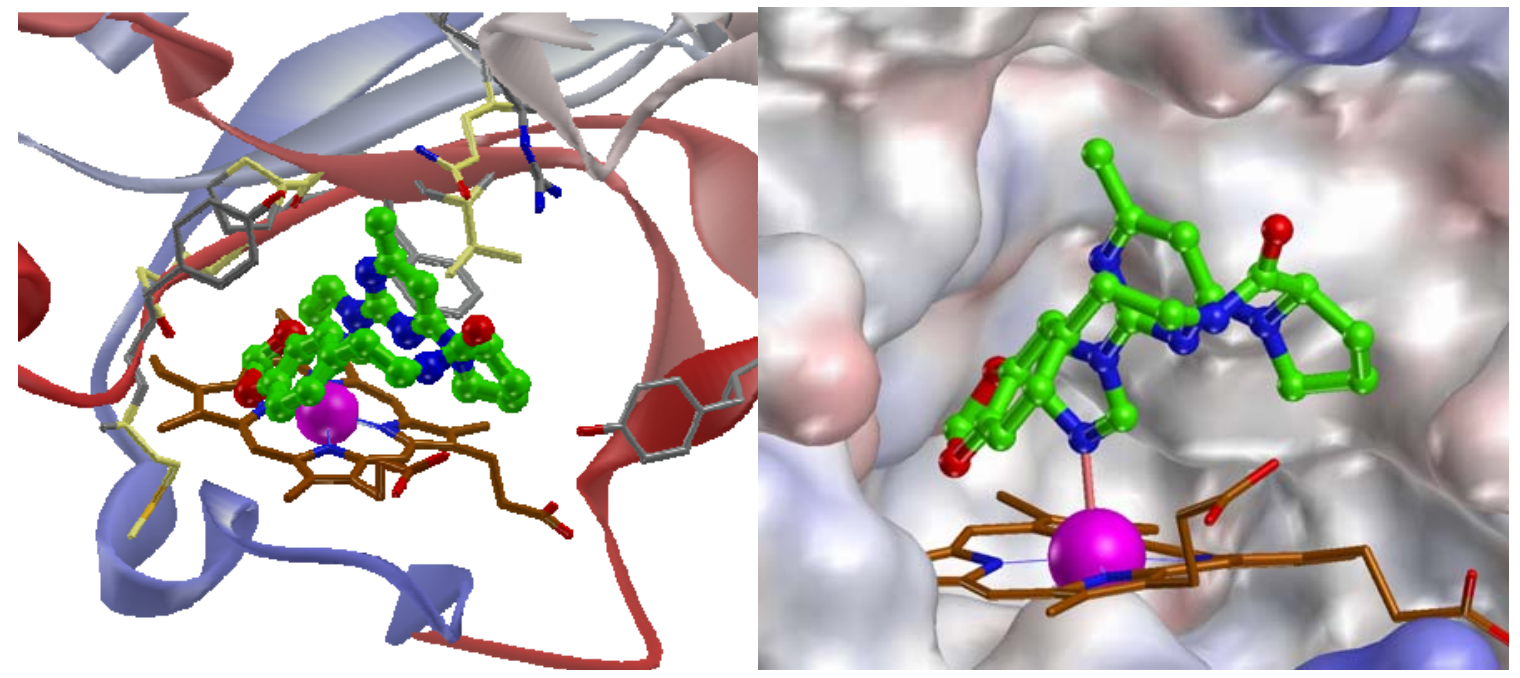

Figure 6. Compound $\mathbf{2 1 b}$ (green carbon atoms) bound to murine iNOS monomer ( $\mathrm{pdb}$ code $2 x x x$ ). The porphyrin is shown in brown and the iron in magenta. (A) A ribbon diagram with the residues that contact the inhibitor $(<4.0 \AA)$. (B) The solvent accessible surface.

A B

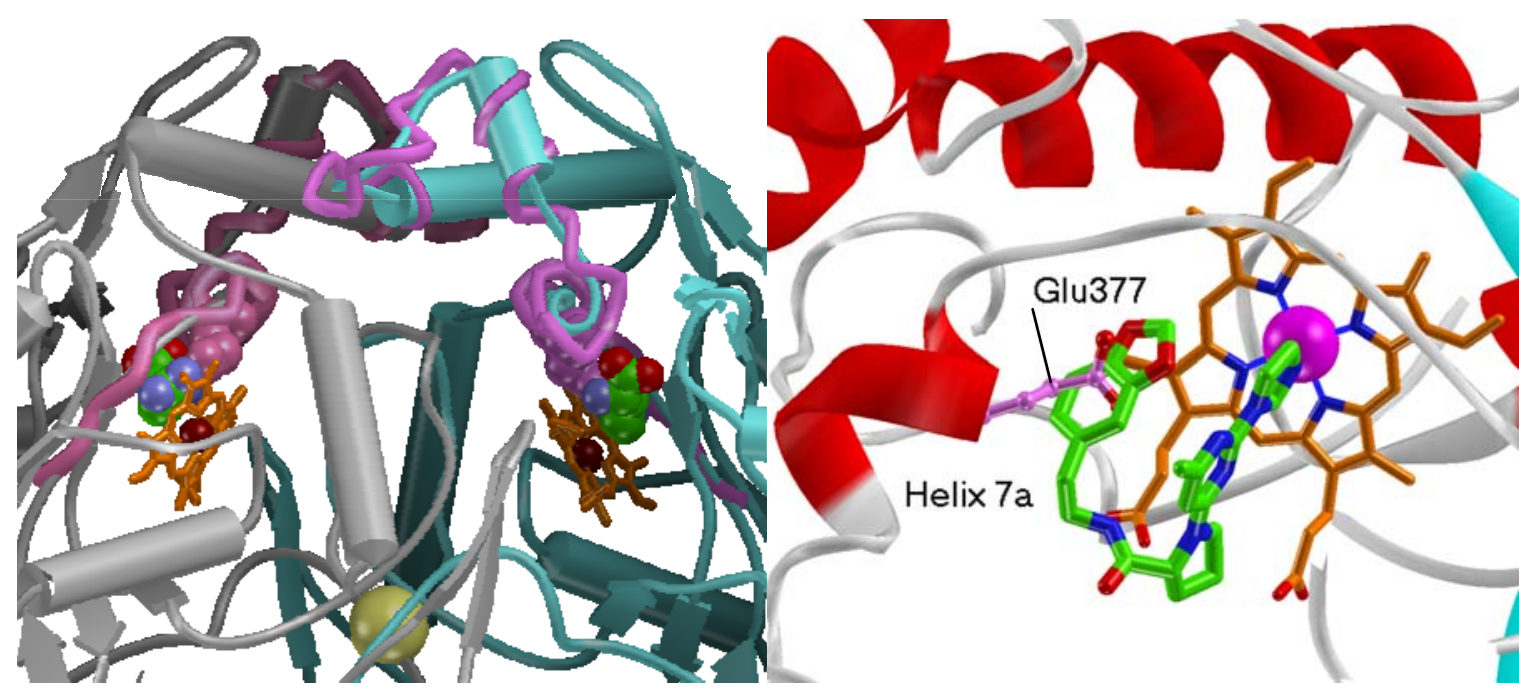

Figure 7. (A) The complex formed with L-Arg (green) and the iNOS dimer. The purple tube denotes the residues that become disordered in the iNOS/21b complex. (B) $\mathbf{2 1 b}$ superimposed on the iNOS dimer complex (1NSI). In 1NSI, Glu377 forms a salt bridge to the guanidine of the arginine substrate. The benzodioxolane of $\mathbf{2 1 b}$ occupies the same space as Glu377. This, presumably, disrupts the folding of helix 7a. 
Scheme 1. Original synthesis of disubstituted pyrimidines

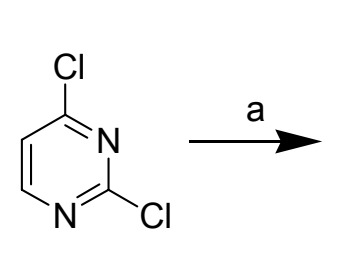<smiles>Clc1nccc(-n2ccnc2)n1</smiles><smiles>Clc1ccnc(-n2ccnc2)n1</smiles>

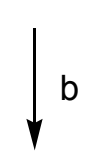
3 $\downarrow$

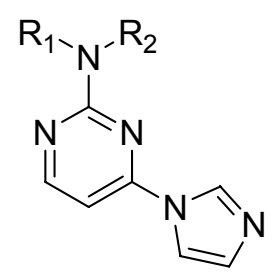<smiles>[R]N([R])c1ccnc(-n2ccnc2)n1</smiles>

Reagents and conditions: (a) imidazole; (b) amine/ $\mathrm{K}_{2} \mathrm{CO}_{3} / \mathrm{DMSO} /$ heat

Scheme 2. Synthesis of 2-pyrimidinesulfone<smiles>COS(=O)(=O)c1nccc(Cl)n1</smiles>

Reagents and conditions: (a) Mel, $\mathrm{K}_{2} \mathrm{CO}_{3}$, DMSO; (b) $\mathrm{POCl}_{3}$, heat; (c) mCPBA, $\mathrm{CH}_{2} \mathrm{Cl}_{2}$ 
Scheme 3. Synthesis of piperazine analogues<smiles>CCOC(=O)CC1CN(C(=O)OCC(C)(C)C)CCN1</smiles><smiles>[R]N1CCN(c2ccnc(-n3ccnc3)n2)C(CC(=O)NCc2ccc3c(c2)OCO3)C1</smiles>

11<smiles>CCOC(=O)CC1CN(C(=O)OC(C)(C)C)CCN1c1ccnc(-n2ccnc2)n1</smiles>

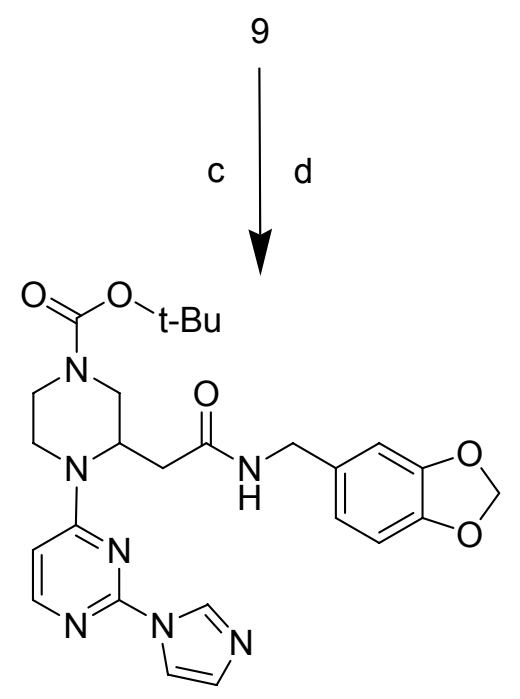

10

a) $\mathrm{K}_{2} \mathrm{CO}_{3}$ /heat; b) Imidazole/heat; c) LiOH/THF; d) Carbonyldiimidazole/piperonylamine; e) TFA/ $\mathrm{CH}_{2} \mathrm{Cl}_{2}$; f) Standard methods 
Table of Contents Graphic

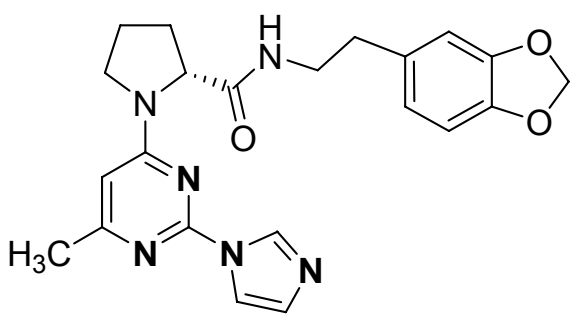

21b 